\title{
Are imputation credits capitalised into stock prices?
}

\author{
Kai-Wei (Shaun) Siau ${ }^{\mathrm{a}}$, Stephen J. Sault ${ }^{\mathrm{b}}$, Geoffrey J. Warren ${ }^{\mathrm{b}}$ \\ ${ }^{a}$ Hong Leong Investment Bank, Kuala Lumpur, Malaysia \\ ${ }^{\mathrm{b}}$ Research School of Finance, Actuarial Studies and Applied Statistics, College of Business and \\ Economics, Australian National University, Canberra, ACT, Australia
}

\begin{abstract}
We investigate whether imputation tax credits are capitalised into Australian stock prices by utilising discounted cash-flow valuation models and examining the relation between earnings yields and imputation credit yields. While imputation credits are valuable to many investors, the evidence that they are reflected in share prices is at best mixed and largely unconvincing. Our results reveal that imputation credits fail to lower realised returns casting doubts over whether imputation credits are priced from the perspective of longer-term buyand-hold investors. If so, such investors can expect to fully benefit from their imputation credits, and imputation effects may not impact on the cost of capital.
\end{abstract}

Key words: Dividend imputation; Share valuation; Cost of capital

JEL classification: G11, G12, G18

doi: $10.1111 /$ acfi. 12058

\section{Introduction}

The introduction of the dividend imputation tax system in July 1987 made tax credits available to eligible Australian investors, such as resident stockholders and superannuation funds, to be redeemed against tax liabilities. The intent of this tax system is to remove the double taxation of dividends at the corporate and personal levels. By redeeming these imputation credits,

The authors are grateful for comments from Paul Brunker, Jozef Drienko, Doug Foster, Jason Hall, Raymond Liu, Phong Ngo, Shuping Shi and Garry Twite; as well as participants at the J.P. Morgan Quant Conference in July 2012. We would also like to thank the editor and an anonymous referee for their helpful suggestions.

Received 18 June 2013; accepted 11 October 2013 by Henk Berkman (Editor). 
stockholders effectively receive an additional source of pre-tax income alongside cash dividends. The extent to which imputation credits are valued in the market has important implications for the pricing of companies, the return required by investors and consequently the cost of capital. Despite a large number of studies, the market value of imputation credits remains broadly disputed (see Gray and Hall, 2006; Gray, 2008; Lally, 2008; Partington and Truong, 2008). The majority of empirical studies have drawn inferences by focusing on the pricing of dividend distributions. This includes analysis of stock price declines around ex-dividend dates ('ex-dividend drop-off studies') and comparative pricing of instruments that differ only in their dividend and imputation entitlements. These studies are subject to a number of issues, such as imprecise estimates that may be influenced by the presence of short-term traders arbitraging dividends and limited samples in the case of comparative studies. Uncertainty over the issue is heightened by the work of Lajbcygier and Wheatley (2012). These authors examine a range of pricing models and find no evidence that the existence of imputation credits is associated with lower realised returns, as might be expected if they were valued by the market. These results set up an interesting conundrum: while there are signs of some influence on pricing and return patterns around dividend events, there is no evidence that imputation credits have an impact on the level of returns achieved by investors over time.

We contribute to this topic by examining whether the existence of imputation credits influences the observed level of stock prices. That is, we directly evaluate the extent to which imputation credits are capitalised by the market. The intuition for our approach is that if available imputation credits are valued by the marginal investor, then the cost of capital will be lower and/or the cash flows recognised by the market are raised, and hence, stock prices will be higher (see Officer, 1994; Dempsey and Partington, 2008). We use two main methods. First, we examine whether an estimate of the present value of imputation credits assists in explaining the distribution of stock prices under an application of the Gordon and Gordon (1997) discounted cash-flow (DCF) valuation model with inputs based on consensus analyst forecasts. Second, we investigate whether imputation credits help to explain the distribution of 1-year forward earnings yields $(F E Y \mathrm{~s})$ under a multiple regression that includes control variables to proxy for aspects such as differences in risk and growth potential. We also extend the analysis through applying the clean surplus accounting model of Ohlson (1995). The underlying notion is that imputation credits should lead to higher stock prices and lower earnings yields, to the extent that such credits are valued by the market.

We study a sample of 468 publicly listed stocks over fiscal years 1996-1997 to 2010-2011, that is, between July 1996 and June 2011. While our results vary by method and sample, overall we fail to find clear, unambiguous evidence that the presence of imputation credits substantially influences the level of share prices. Evidence in support of the notion that imputation credits 
might be priced arises from multiple regressions of share price on estimates of the present value of both equity cash flows (i.e. dividends and terminal earnings) and imputation credits. These regressions reveal a coefficient on imputation credit that suggests they may be priced at around 30 cents per dollar. However, reasons exist to question the substance of this finding. Firstly, the coefficient estimates need to be treated with some caution due to high multicollinearity between the present value of imputation credits and equity cash flows. Second, the incremental $R$-squared relative to a specification including only the present value of equity cash flows was minor at around +0.1 per cent. The latter suggests that imputation credits provide little additional assistance in explaining the distribution of share prices over and above a DCF model based on equity cash flows alone, thus casting doubt over their economic relevance. Further analysis uncovers no signs that imputation credits impact on share price levels. Portfolio sorts, initially by imputation credit yield and then double-sorting by dividend yield and imputation credit yield, suggest that the presence of imputation credit yields $(I C Y)$ does not assist in explaining the distribution of share prices relative to a DCF model based only on the present value of equity cash flows. Analysis of earnings yields reveals a significantly positive relation with $I C Y$, even when dividend yields $(D Y)$ are included in the specification. This relation indicates that the presence of imputation credits raises earnings yields, which is the opposite of what might be expected if imputation credits were priced at the margin. Robustness testing generates comparable findings, although we note that the contribution of imputation credits to explaining prices was stronger under the Ohlson (1995) model, while analysis of a subsample excluding resource stocks produces results that are similar but amplified relative to those for the full sample.

If imputation credits were incorporated into market prices, they should leave clear footprints in both the overall level of share prices and the returns realised by investors over the passage of time. However, the trail is at best faint and confusing. Signs that imputation credits are priced emerge only from multiple regression tests of various DCF models, where multicollinearity is substantial and imputation credits make only a small marginal contribution to explaining prices. Other analysis generates no signs whatsoever that imputation credits are priced, including our portfolio sorts, the analysis of earnings yields and the investigation of realised returns by Lajbcygier and Wheatley (2012). Indeed, at times these other methods leave a trail that seems to head in the wrong direction. When viewed as a body of work, the research fails to provide convincing evidence that imputation credits are priced.

Given that imputation credits are clearly valuable to many investors, what might explain the absence of a clear and consistent association with share price levels and returns? We suggest three possible explanations. The first is that the marginal investor does not value imputation credits, for example, that prices of Australian stocks are set by international investors. The second possibility is 
problems with the empirical methods. In addition to multicollinearity between imputation credits and other explanatory variables, other issues include potential lack of power due to estimation error or noise and the possibility that imputation credits might be correlated with priced factors that are not properly accounted for in the tests. Here the use of a variety of empirical frameworks reduces the risk associated with relying on one method. Indeed, we downplay our DCF-based results based on its particular issues plus the observation that the findings are not confirmed by other methods. A third explanation is that the failure to price imputation credits could reflect a market inefficiency, that is, that the market has 'got it wrong' in attributing no value to imputation credits.

The lack of clear evidence that imputation credits impact on the level of share prices and returns establishes an interesting contrast with analysis of the value of imputation credits by reference to immediate dividend events, that is, exdividend drop-off and comparative pricing studies. While results from these studies are also mixed, the majority have found evidence that imputation credits are partially priced. For instance, the most recent and arguably comprehensive ex-dividend drop-off study by Gray et al. (2011) concludes that franking credits are valued at around $\$ 0.35$ per dollar. The contrasting results between these two strains might be reconciled by the possibility that shorterterm return patterns around dividend events may be influenced by traders or arbitrageurs, while having no impact on the overall level of prices, and hence longer-term returns achieved through time. Meanwhile, our analysis implicitly adopts the perspective of longer-term 'buy-and-hold' investors by examining share prices under the prism of valuation models that view stock prices as representing the value of a future stream of cash flows. Similarly, Lajbcygier and Wheatley (2012) adopt the perspective of long-term investors by analysing average returns over time.

A situation where imputation credits do not raise share prices or lower expected buy-and-hold returns has implications for both investment and costs of capital estimation. Such a situation might be viewed as good news for longer-term investors who can utilise imputation credits. It means they may reap the full benefit from dividend imputation, as it augments total returns without any offset in terms of lower expected market returns. This conclusion holds regardless of whether any failure to price imputation credits arises because they are not valued by the marginal investor, or reflects some form of market inefficiency. For cost of capital estimation, arguably it is the returns expected by long-term investors that are of most consequence in setting the hurdle rate for companies to achieve. If imputation credits are not priced and hence do not influence expected buy-and-hold returns, then it may be more appropriate for them to be excluded when estimating the cost of capital. This would imply setting so-called $\theta=0$ under the commonly used imputationadjusted CAPM (see Gray, 2008). 
The remainder of this study is organised as follows. Section 2 provides background, including discussion of the existing literature and its shortcomings. Section 3 outlines the methods used, while Section 4 summarises our data sample. Section 5 presents our results, with Section 6 concludes the study.

\section{Background}

Since 1 July 1987, Australia has operated a dividend imputation tax system that effectively eliminates the double taxation of dividend income for resident stockholders. Under this system, stockholders receive additional tax credits, or imputation credits, for corporate taxes paid on domestically sourced income. Initially, these credits could be used to offset personal tax liabilities on the cash dividends that were distributed. In July 2000, this was extended by permitting imputation credits to be offset against other tax liabilities under the Rebate Provision. The latter significantly enhanced the value of imputation credits to investors paying tax rates below the corporate level such as superannuation funds, charities and some individuals. However, not all stockholders are fully entitled to these rebates. Most notably, foreign stockholders do not have direct access to imputation credits.

An important question is how the existence of dividend imputation impacts prices and expected returns. Officer (1994) reveals how imputation credits may be accounted for via either reduced cost of capital or increased cash flows, insofar as they can be used to reduce the tax liability of stockholders. Either way, the implication is share prices will be higher to the extent that imputation credits are valued in the market, relative to a classical tax system. The value attributed to imputation credits by the market is of considerable interest for cost of capital estimation, as well as for investors via its potential influence on the returns they may expect and identification of 'fair' market value. The identity of the marginal investor and their tax status is critical in addressing this issue. Although the estimation of the value of imputation credits is straightforward for resident stockholders, the presence of foreign and certain taxexempt stockholders complicates the identification process for two reasons: first, the identity of the marginal investor becomes unclear; and second, if foreign stockholders have the ability to transfer imputation credits to resident stockholders through tax arbitrage activities, then they may be priced at the margin even if foreigners are marginal. Given the variety of investors operating in Australian markets, the value attributed to imputation credits could potentially fall anywhere between zero and 100 per cent of face value.

Extension of the classical CAPM to incorporate the effects of imputation credits is addressed by Officer (1994), Lally (2000), Lally and van Zijl (2003) and Dempsey and Partington (2008). In particular, the Officer (1994) framework is widely employed in practice, especially in regulatory decisions on cost of capital. Officer introduces 'gamma' as the proportion of corporate tax that will eventually be distributed as imputation credits. Gray (2008) observes that 
gamma has since come to be interpreted as the value of imputation credits at the point of creation, reflecting the product of the portion of credits created that are distributed (the 'distribution rate'), and their value to investors at the time they receive them (known as 'theta'). Our interest is in the latter, that is, theta.

The extant literature has used three approaches to estimate the value attributed to the imputation credits by the market: ex-dividend drop-off studies; examination of securities that differ only in their entitlement to dividends and attached imputation credits; and analysis of realised returns. The most pervasive approach in the literature has been drop-off studies, which infer the market value of imputation credits from the decline exhibited by stock prices on the ex-dividend date. Notable Australian studies include Brown and Clarke (1993), Bellamy (1994), Walker and Partington (1999), Hathaway and Officer (2004), Beggs and Skeels (2006), Gray (2008), Feuerherdt et al. (2010), Minney (2010) and Gray et al. (2011). Ex-dividend price declines stem from the loss in value directly attributable to stockholders ceasing to be eligible for the forthcoming dividend. The market value of imputation credits is estimated by regressing the stock price drop observed on the ex-dividend date against the face value of the dividend and associated imputation credits. Insofar as dividends are taxed at a different rate to capital gains, a phenomenon referred to as the tax differential effect, the drop-off ratios may deviate from one. These studies generate a market value for imputation credits by attributing the observed drop-off between the value of cash dividends and attached imputation credits, respectively. This is done either by imposing an assumed market value for cash dividends (e.g. a coefficient of 0.80 is imposed by Hathaway and Officer, 2004) or by adopting the coefficients arising from a multiple regression (e.g. Beggs and Skeels, 2006).

Although widely employed in the literature, drop-off analysis can produce market value estimates that are largely inconsistent across studies. This aspect has been a feature since the development of the method and its application to U.S. data (Duran and May, 1960; Elton and Gruber, 1970). In the case of Australian studies, estimates of the market value of imputation credits have ranged from $\$ 0.20$ per dollar and below (e.g. some of the estimates reported by Brown and Clarke, 1993; and Gray et al., 2011) to well over $\$ 0.60$ (e.g. Walker and Partington, 1999; Minney, 2010). No widely accepted value for imputation credits arises from this body of work. Nevertheless, an initial view emerged that imputation credits were priced at around $\$ 0.50$ per dollar, consistent with the suggestion of Hathaway and Officer (2004). However, the recent drop-off study by Gray et al. (2011) might be considered 'state of the art' in terms of data cleansing and breadth of models. These authors conclude that imputation credits are valued at around $\$ 0.35$ based on the drop-off analysis.

The variability in estimates joins with issues over design to cast some doubt over estimates for the market value of imputation credits arising from dropoff studies. A key methodological issue is that price movements around ex-dividend events encapsulate not only the tax differential effect, but may also 
reflect the presence of traders seeking to arbitrage dividends and noise associated with trading activity around ex-dividend dates. Drop-off ratios can be distorted by the need to compensate traders for transaction costs (Eades et al.,1984; Lakonishok and Vermaelen, 1986; Karpoff and Walkling, 1988, 1990; Bali and Francis, 2011) or the risk involved (Heath and Jarrow, 1988; Grammatikos, 1989; Fedenia and Grammatikos, 1993; Michaely and Vila, 1995). Transaction costs may be substantial and can drive the drop-off ratio below one (Kalay, 1982, 1984; Boyd and Jagannathan, 1994). Market microstructure effects may also complicate estimation of market value, as discrete tick sizes can bias drop-off ratios downwards (Dubofsky, 1992; Bali and Hite, 1998). ${ }^{1}$

A further key methodological issue is the difficulty in attributing the observed drop-off value between cash dividends and imputation credits. Dempsey and Partington (2008) nominate this identification problem as a serious limitation of ex-dividend drop-off studies. Drop-off studies are afflicted by multicollinearity issues, with Cannavan et al. (2004) and Bellamy and Gray (2006) observing that imputation credits are nearly perfectly collinear with their respective cash dividends. This is exacerbated by corporate tax rates being almost constant and partially franked dividends being the exception rather than the norm. Gray (2008) points out that the value attributed to imputation credits is conditional on the assumed value on cash dividends by design, to the extent that they are supplementary components within a single package. This notion is reinforced by evidence of offsetting variation in the value attributed to dividends and imputation credits across samples (see Bellamy and Gray, 2006; Gray, 2008).

Two studies estimate the market value of imputation credits by comparing the pricing of different instruments with identical characteristics except for their entitlement to forthcoming dividends. Twite and Wood (2003) compare individual stock futures (ISFs) with the underlying shares for ten stocks during 1994-1995. They find that imputation credits are priced at around $\$ 0.45$ per dollar. Cannavan et al. (2004) consider both ISFs and low exercise price options (LEPOs) between 1994 and 1999. They uncover some evidence that imputation credits are valued prior to July 1997, when the 45-day rule was introduced to prevent trading of these credits, but no evidence they are valued thereafter. Comparative pricing methods overcome some of the estimation issues of drop-off studies, including generating more stable estimates determined under no-arbitrage conditions that are relatively unaffected by noise induced by abnormal trading activities. However, by focusing on relative

\footnotetext{
${ }^{1}$ This issue is slightly mitigated as tick sizes have been almost continuous in recent years (Graham et al., 2003; Jakob and Ma, 2004). Nevertheless, bid-ask spreads may still materially alter drop-off ratios by introducing biases in the cum-dividend and exdividend stock prices used to calculate the drop-off ratios (Frank and Jagannathan, 1998).
} 
pricing with regard to specific dividend events, they do not directly address the issue of whether the imputation credits influence the overall level of prices and expected returns. Further, samples used tend to lack representativeness, involving data for a relatively small number of stocks drawn from the mid-late 1990s.

Although it has been recognised for some time that the availability of imputation credits should lower expected returns to the extent that they are valued by the market (for instance, see Officer, 1994), the relation between returns and imputation credits has been closely examined only recently by Lajbcygier and Wheatley (2012). These authors find no evidence that the presence of imputation credits is associated with lower realised returns under a range of asset pricing models. Indeed, they find a positive relation between realised returns and imputation credits, which is significant under some specifications. That is, they find that stocks offering higher ICY tend to generate higher returns after controlling for a variety of recognised factor exposures, implying a negative value on imputation credits. Given that the lower bound on the value of imputation credits is zero, it seems likely that these results are explained by the credits acting as a proxy for unobserved factors not captured by their pricing models. Further, the ability to detect any relation may be hampered by the noisy nature of return data as a proxy for expected returns, given that $I C Y$ are relatively modest in magnitude and stable as compared to returns. ${ }^{2}$ Nevertheless, the results of Lajbcygier and Wheatley (2012) only deepen the uncertainty over the value attributed to imputation credits by the market.

In summary, the extant literature has produced inconsistent estimates of the market value of imputation credits, while the methods used are subject to various issues. One gap in the literature is a test of the proposition that share prices should be higher to the extent that imputation credits are valued by the marginal investor (see Officer, 1994). This is the gap we aim to fill.

\section{Method}

Our approach involves examining the impact of imputation credits on the level of stock prices, after conditioning on consensus analyst forecasts for dividends and earnings. The assumption is that the market will set higher stock prices conditional on such forecasts if imputation credits provide additional value to the marginal investor, controlling for other factors that may determine stock prices. We employ two main methods towards this purpose: a DCF valuation model and an analysis of $F E Y$ s. We also report

\footnotetext{
${ }^{2}$ We took the opportunity to reinvestigate the relation between returns and imputation credits under both the CAPM and 3-factor model of Fama and French (1993), including using 6-month returns to span dividend events. The results were similar to Lajbcygier and Wheatley (2012), thus confirming their findings.
} 
results using the model of Ohlson (1995) under robustness testing. The analysis implicitly assumes that consensus analyst forecasts provide a fair representation of the cross-sectional distribution of the dividends and earnings that are expected by the marginal investor who prices stocks. ${ }^{3}$ This follows previous research that uses analyst forecasts to proxy for market expectations in addressing asset pricing issues, notably the literature on implied cost of capital (see Fitzgerald et al., 2013; Guay et al., 2011). We also assume that the future imputation credits expected by the marginal investor can be derived from the most recently observed franking levels and corporate tax rates.

Our approach provides alternative perspectives on the valuation of imputation credits that face issues that are not of entirely the same nature as other methods. By abstracting from the pricing of dividend events, our approach disengages from the influence of short-term traders. This grants an opportunity to gauge the value of imputation credits from the perspective of long-term investors who may determine the overall level of prices and expected returns through time. Our approach facilitates analysis of a broader sample than the comparative pricing studies, as analyst forecast data are available for a wide range of stocks. Relative to analysis of returns, our approach is arguably not as subject to the influence of either noise or unobserved factors appearing in realised returns that may be correlated with imputation credits. Of the issues faced by our approach, two are most notable: one is the high correlation between imputation credits and dividends, which can lead to identification issues under our regression specifications - a problem that is shared with drop-off studies; and the other issue is the possibility that our measures of the equity cash flows and imputation credits expected by the market might contain errors. We attempt to limit exposure to these issues by examining our data using a variety of methods and subsamples.

\subsection{Analysis of prices under a DCF valuation model}

Our first set of tests involves evaluating the extent to which an estimate of the present value term for imputation credits makes a contribution to explaining the distribution of observed stock prices under a DCF valuation model. The model employed is a version of the Gordon and Gordon (1997) DCF valuation model, extended to include a term for the present value of

\footnotetext{
${ }^{3}$ The consistency between underlying 'true' market expectations, analyst forecasts and market prices is open to conjecture. Fitzgerald et al. (2013) suggest that analyst target prices may be more consistent with analyst forecasts than market prices. On the other hand, Clarkson et al. (2012) find evidence that analyst target prices may be also influenced by behavioral anchors, in addition to fundamentals. In any event, we were unable to analyse analyst target prices for Australian companies due to lack of data.
} 
imputation credits. This approach is based on the notion that the intrinsic value of a stock reflects the present value of all expected future cash flows. If imputation credits are available and valued as an additional source of income to the marginal investor, then stock prices should be commensurately higher. However, we encounter the issue that present value estimates for imputation credits and equity cash flows are highly correlated, which can make the attribution of explanatory power between the two variables unreliable under multiple regression analysis. Hence, we also focus on the marginal contribution of imputation credits in reconciling share prices under our DCF model through examining the change in $R$-squared from adding the imputation credit term relative to a baseline regression including only the present value of equity cash flows. We also undertake portfolio sorts to investigate how the ratio between price and the present value of equity cash flows varies with imputation credits, on the basis that an increasing premium over the valuation of equity cash flows should be apparent if imputation credits are valued by the market.

We now detail our DCF model. Equations (1) and (2) are general expressions for price as the net present value of future distributions, including imputation credits to the extent that they are valued by the market. It indicates that stock prices should be positively related to imputation credits distributed by stocks, insofar as the marginal investor ascribes value to these credits as reflected in the coefficient $\phi$. This relation is similar to that derived by Ashton (1991) in adapting the traditional CAPM to the dividend imputation tax system.

$$
\begin{aligned}
p_{k_{t}} & =\frac{\mathbb{E}\left(d_{k_{t+1}}\right)+\phi \mathbb{E}\left(i c_{k_{t+1}}\right)}{1+\mathbb{E}\left(\gamma_{k_{t+1}}^{e}\right)}+\frac{\mathbb{E}\left(d_{k_{t+2}}\right)+\phi \mathbb{E}\left(i c_{k_{t+2}}\right)}{\left(1+\mathbb{E}\left(\gamma_{k_{t+2}}^{e}\right)\right)^{2}}+\frac{\mathbb{E}\left(d_{k_{t+3}}\right)+\phi \mathbb{E}\left(i c_{k_{t+3}}\right)}{\left(1+\mathbb{E}\left(\gamma_{k_{t+3}}^{e}\right)\right)^{3}}+\cdots \\
& =\sum_{i=1}^{\infty} \frac{\mathbb{E}\left(d_{k_{t+i}}\right)+\phi \mathbb{E}\left(i c_{k_{t+i}}\right)}{\left(1+\mathbb{E}\left(\gamma_{k_{t+i}}^{e}\right)\right)^{i}} \\
p_{k_{t}} & =\sum_{i=1}^{\infty} \frac{\mathbb{E}\left(d_{k_{t+i}}\right)\left(1+\phi \frac{\tau_{t}^{c}}{1-\tau_{t}^{c}} \gamma_{k_{t}}\right)}{\left(1+\mathbb{E}\left(\gamma_{k_{t+i}}^{e}\right)\right)^{i}}
\end{aligned}
$$

where:

$p_{k_{t}}=$ price of stock $k$ at period $t$;

$d_{k_{t}}=$ face value of dividends received from stock $k$ in period $t$;

$i c_{k_{t}}=$ imputation credits distributed by stock $k$ in period $t$; 
$\Phi=$ utilisation of imputation credits by the marginal investor, which equates to the market value of a dollar of imputation credits;

$\gamma_{k_{t}}=$ franking percentage for stock $k$ in period $t$;

$\tau_{t}^{c}=$ statutory corporate tax rate for period $t$; and

$\mathbb{E}\left(\gamma_{k_{t}}^{e}\right)=$ cost of equity for stock $k$ with respect to period $t$

To implement this general expression, we modify the Gordon and Gordon (1997) finite horizon valuation model, by discounting a limited number of future dividend per share estimates for years $t+1$ and $t+2$, and capitalising earnings per share $(E P S)$ in year $t+3$ at a real discount rate. The capitalisation of 'terminal' earnings in this manner implicitly assumes that earnings in year $t+3$ are a good proxy for maintainable cash flows, that is, a real income stream available for distribution in perpetuity. ${ }^{4}$ The Gordon and Gordon (1997) model appears to have lower pricing errors than competing valuation models (see Lee et al., 2010; Hou et al., 2012), implying that it should generate more robust findings. Equation (3) defines the two components under the empirical application of our DCF valuation model. Equation (3a) describes the present value of equity cash flows, denoted as $P V\left(D_{k_{t}}\right)$, which comprise dividends plus capitalisation of terminal earnings. Equation (3b) describes the present value of imputation credits, $P V\left(I C_{k_{t}}\right)$. Equation (4) sets out the OLS regression that we estimate. Fiscal year fixed effects are included in the regressions to account for heterogeneity across time, with standard errors clustered by both time and firm (see Petersen, 2009).

$$
\begin{aligned}
& P V\left(D_{k_{t}}\right)=\mathbb{E}_{t}\left(\frac{D P S_{k_{t+1}} T}{\left(1+\gamma_{k_{t}}^{e}\right)^{T}}+\frac{D P S_{k_{t+2}}}{\left(1+\gamma_{k_{t}}^{e}\right)^{T+1}}+\frac{E P S_{k_{t+3}}}{\left(\gamma_{k_{t}}^{e}-I n f\right)\left(1+\gamma_{k_{t}}^{e}\right)^{T+1}}\right) \\
& P V\left(I C_{k_{t}}\right)=\left(\frac{\tau_{t}^{c}}{1-\tau_{t}^{c}} \gamma_{k_{t}}\left(\frac{D P S_{k_{t+1}} T}{\left(1+\gamma_{k_{t}}^{e}\right)^{T}}+\frac{D P S_{k_{t+2}}}{\left(1+\gamma_{k_{t}}^{e}\right)^{T+1}}+\frac{E P S_{k_{t+3}}}{\left(\gamma_{k_{t}}^{e}-I n f\right)\left(1+\gamma_{k_{t}}^{e}\right)^{T+1}}\right)\right)
\end{aligned}
$$

\footnotetext{
4 This formulation implicitly assumes that either earnings are fully distributed, or alternatively and equivalently that any earnings reinvested will earn the cost of equity and thus create no additional value.
} 


$$
P_{k_{t}}=\beta_{0}+\beta_{1} P V\left(D_{k_{t}}\right)+\beta_{2} P V\left(I C_{k_{t}}\right)+\tilde{\varepsilon}_{k_{t}}
$$

where:

$P V\left(D_{k_{t}}\right)=$ estimated present value of expected equity cash flows for stock $k$ at period $t$;

$P V\left(I C_{k_{t}}\right)=$ estimated present value of expected imputation credits for stock $k$ at period $t$

$P_{k_{t}}=$ observed price of stock $k$ at period $t$;

$D P S_{k_{t+i}}=$ consensus analyst forecast of dividends per share (DPS) for fiscal year $i$ of stock $k$ formed at period $t$;

$E P S_{k_{t+i}}=$ consensus analyst forecast of EPS for fiscal year $i$ of stock $k$ formed at period $t$;

Inf $=$ assumed inflation beyond period $t+3$, set at 2.5 per cent;

$\tau_{t}^{c}=$ statutory corporate tax rate at period $t$;

$\gamma_{k_{t}}=$ franked proportion of distributed dividends for stock $k$ in period $t$;

$\gamma_{k_{t}}^{e}=$ cost of equity for stock $k$ at period $t$; and

$T=$ number of months between period $t$ and the fiscal year end of stock $k$, represented as a fraction of a year, with the first year dividend forecast scaled by a fraction to account for dividends that no longer accrue at the time of valuation.

Consensus analyst forecasts are utilised as proxies for investor expectations for dividend and earnings. There is some evidence that these forecasts reasonably reflect investor expectations (O'Brien, 1988; Frankel and Lee, 1998) and are moderately accurate over the short to medium term (Brown et al., 2008). However, analyst forecasts are also known to be upwardly biased (Hayes and Levine, 2000; Easton and Sommers, 2006). Any such bias is likely to be of limited consequence in the current circumstances. As we are primarily interested in the cross-section of stock prices, our results should remain valid providing that imputation credits are uncorrelated with forecast errors. Further, any persistent upward forecast bias across all stocks should manifest in the regression constant and a higher implied equity risk premium (ERP; see Discussions below) and hence should not distort the slope estimates to any meaningful extent.

With respect to the statutory corporate tax rate and the proportion of dividends franked, we assume that both remain unchanged in future relative to that observed at the time of valuation. We argue that this assumption is reasonable with respect to tax rates as they are not volatile (Grubert, 2001). In addition, Bellamy (1994) provides evidence that imputation distributions are persistent. On the other hand, while the franking percentage does vary over time, such changes are difficult to predict. In any event, the prevailing level of taxation and franking represents the best proxy we have available for market expectations at the time of valuation. 
The cost of equity for each stock is estimated using the traditional CAPM. Betas were generated using 48-month rolling regressions and corrected using the method of Blume (1971) applying a coefficient of 0.67 for regression towards the mean. ${ }^{5}$ Generating an estimate for the ex ante ERP is more problematic, as it is endogenous to the model. That is, the market-wide ERP should itself be a function of the extent to which imputation credits are valued in the market (Gray and Hall, 2006). This gives rise to an identification problem. To deal with this issue, we impose external ERP estimates. We commence with an ERP of 6 per cent (see Brailsford et al., 2008; Fernandez et al., 2011), but repeat the analysis at ERPs from 4 and 8 per cent. This ERP range is designed to incorporate any potential effects induced by imputation credits, ${ }^{6}$ while spanning estimates that are generally considered plausible. Our results suggest that the ERP implied in market prices is centred around 6 per cent.

\subsection{Analysis of earnings yields}

Similar to the discussion under Section 3.1., stock prices should also be higher relative to earnings if imputation credits are valued by the market. We test this proposition by regressing earnings yields (earnings/price ratios) on $I C Y$ plus a range of control variables that might assist in explaining the cross-section of earnings yields. To motivate the identification of control variables, we refer to the fundamental valuation framework of Miller and Modigliani (1961). Under the assumption that earnings provide a proxy for maintainable cash flows (i.e. could be distributed in perpetuity), Miller and Modigliani (1961) propose that stock prices are the sum of the capitalised value of earnings plus the present value of growth opportunities (PVGOS). Equation (5) describes this relation.

$$
p_{k_{t}}=\frac{\mathbb{E}\left(e_{k_{t+1}}\right)}{\gamma_{k_{t}}^{e}}+P V G O_{k_{t}}
$$

\footnotetext{
${ }^{5}$ Blume betas were estimated as $0.33+0.67 *$ OLS Beta. The coefficient of 0.67 is broadly consistent with Brooks and Faff (1997) and Statman (1981) and aligns with that used by Bloomberg. Applying this correction generated more plausible results under the DCF analysis, as outlying betas led to implausible cost of capital estimates and hence DCF valuations when raw OLS betas were employed. This choice has no impact on the earnings yield results, as the Blume correction effectively amounted to a scaling parameter in that context. Corrections for thin trading were investigated using the method of Dimson (1979), but made little difference to the results.

${ }^{6}$ Applying the Officer (1994) adjustment for the cost of equity, the ERP is adjusted upwards to incorporate the value of imputation credits. Given that the historical imputation credit yield is 1.4 per cent, a range of \pm 2 per cent should account for the potential effects of imputation credits on ERP assumptions.
} 
where

$\mathbb{E}\left(e_{k_{t+1}}\right)=$ expected future EPS for stock $k$ at period $t+1$;

$\gamma_{k_{t}}^{e}=$ cost of equity for stock $k$ for period $t$; and

$P V G O_{k_{t}}=$ present value of growth opportunities expected for stock $k$ at period $t$.

Equation (6) extends the Miller and Modigliani (1961) framework by incorporating imputation credits as an additional component of value. ${ }^{7}$ This expression suggests that a stock's $F E Y(E / P$ ratio $)$ is positively related to the cost of equity $r_{k_{t}}^{e}$ and, by implication, risk; negatively related to expected growth; and negatively related to the expected imputation credit yield, to the extent that imputation credits are valued by the market.

$$
\begin{aligned}
& P_{k_{t}}=\frac{\mathbb{E}\left(e_{k_{t+1}}\right)+\phi \mathbb{E}\left(f_{k_{t+1}}\right)}{\gamma_{k_{t}}^{e}}+P V G O_{k_{t}} \\
& \frac{\mathbb{E}\left(e_{k_{t+1}}\right)}{p_{k_{t}}}=\gamma_{k_{t}}^{e}-\frac{\gamma_{k_{t}}^{e} P V G O_{k_{t}}}{p_{k_{t}}}-\frac{\phi \mathbb{E}\left(f_{k_{t+1}}\right)}{p_{k_{t}}}
\end{aligned}
$$

We implement the earnings yield model by employing various control variables for risk and growth potential. Our proposed OLS regression model is described by Equation (7). The dependent variable is the 1-year FEY, reflecting the ratio between consensus EPS for period $t+1$ and the share price at period $t$. The risk controls include CAPM beta $(\beta), \log$ of market capitalisation $(\ln (M V))$ and leverage $(D / A)$. Growth proxies include the bookto-market ratio $(B / M)$, consensus EPS growth between period $t+1$ and $t+3$ $(g 3 v 1)$ and consensus long-term earnings growth $(g L T)$. We note that $\ln (M V)$ and $B / M$ are characteristic-based equivalents to the SMB and HML factors of Fama and French (1993). Additionally, to allay concerns of the imputation credit yield mirroring any effect related to dividends, we further include a term for DYs. Initial analysis revealed the terms related to long-term earnings growth and leverage to be insignificant. These were subsequently dropped from the analysis, which permitted an expansion in sample size. Fiscal year fixed effects are included in the regressions to account for heterogeneity across time, with standard errors clustered by both time and firm (see Petersen, 2009).

7 Equation (6) assumes that the expected imputation credit in period $t+1$ is maintainable in perpetuity. 


$$
\begin{aligned}
F E Y_{k_{t}}=\frac{\mathbb{E}_{t}\left[E P S_{k_{t+1}}\right]}{P_{k_{t}}}= & \gamma_{0}+\gamma_{1} I C Y_{k_{t}}+\gamma_{2} \hat{\beta}_{k_{t}}+\gamma_{3} \ln \left(M V_{k_{t}}\right)+\gamma_{4}(B / M)_{k_{t}} \\
& +\gamma_{5} \mathbb{E}_{t}\left[g 3 v 1_{k_{t+1}}\right]+\gamma_{6} D Y_{k_{t}}+\gamma_{7} \mathbb{E}_{t}\left[g L T_{k_{t+1}}\right] \\
& +\gamma_{8}(D / A)_{k_{t}}+\tilde{\varepsilon}_{k_{t}}
\end{aligned}
$$

where

$F E Y_{k_{t}}=1$-year forward earnings yield for stock $k$ formed at period $t$;

$E P S_{k_{t+i}}=$ consensus analyst forecast of 1-year forward EPS of stock $k$ formed at period $t$;

$P_{k_{t}}=$ observed price of stock $k$ at period $t$;

$I C Y_{k_{t}}=$ realised imputation credit yield on stock;

$\hat{\beta}_{k_{t}}=$ CAPM beta of stock $k$ 's stock at period $t$, estimated by OLS regression over prior 48 months with correction of Blume (1971) applied;

$\ln \left(M V_{k_{t}}\right)=$ natural logarithm of market capitalisation of stock $k$ at period $t$;

$(B / M)_{k_{t}}=$ book-to-market ratio of stock $k$ at period $t$, equals ratio of book equity to market equity;

$g 3 v 1_{k_{t}}=$ annualised growth in consensus analyst EPS forecasts between period $t+1$ and period $t+3$ for stock $k$ formed at period $t$;

$D Y_{k_{t}}=$ realised dividend yield on stock $k$ at period $t$;

$g L T_{k_{t}}=$ consensus analyst forecast of long-term earnings growth rate for stock $k$ formed at period $t$; and

$(D / A)_{k_{t}}=$ leverage of stock $k$ at period $t$, calculated as the ratio of total debt to total assets.

One issue with the regression as specified in Equation (7) is that some variables are scaled by a common divisor. Specifically, $F E Y, I C Y, D Y$ and $B / M$ are all scaled by the share price or equivalent. The implication is that $R$-squared and significance levels need to be interpreted cautiously (see Powell et al., 2009). We note that the DCF model does not suffer from this issue. Accordingly, the two models can be viewed as complementary.

\subsection{Supplementary analysis and robustness checks}

We further validate our analysis in three ways: first, we evaluate an alternative valuation model derived from clean surplus accounting theory (Ohlson, 1995). Specifically, we assess the impact of imputation credits on stock prices after addressing the effects of known attributes, including book value, trailing EPS and forward EPS (Collins et al., 1997; Bettman, 2007; Bettman et al., 2009). The specification is described in equation (8). This model has the added benefit that there are no econometric concerns related to common divisors, as discussed above. Fiscal year fixed effects are included in the regressions to account for heterogeneity across time, with standard errors clustered by both time and firm (see Petersen, 2009). 


$$
P_{k_{t}}=\rho_{0}+\rho_{1} B V_{k_{t}}+\rho_{2} E P S_{k_{t}}+\rho_{3} \mathbb{E}_{t}\left[E P S_{k_{t+1}}\right]+\rho_{4} I C_{k_{t}}+\tilde{\varepsilon}_{k_{t}}
$$

where

$P_{k_{t}}=$ price of stock $k$ at period $t$;

$B V_{k_{t}}=$ book value per share of stock $k$ in period $t$;

$E P S_{k_{t}}=$ trailing EPS of stock $k$ at period $t$;

$E P S_{k_{t+1}}=$ consensus analyst forecast of 1-year forward EPS of stock $k$ formed at period $t$; and

$I C_{k_{t}}=$ face value of imputation credits distributed by stock $k$ at period $t$.

Second, we estimate results for our baseline models across various subsamples. We investigate the impact of tax regimes by generating results before and after the Rebate Provision that came into effect on 1 July 2000. Estimates are also generated for each fiscal year. Industry effects are evaluated through estimating our models on a sample that excludes the resource sector, and for four broad industry sectors (consumer related, financials, other industrials and resources). We gauge the impact of small stocks by analysing two subsamples that exclude stocks below two different market capitalisation cut-off levels of $\$ 200$ million and \$500 million, respectively.

Third, we run robustness tests involving alternative explanatory variables. We repeat the DCF and earnings yield analysis using mean rather than median consensus analyst forecasts. While most studies employ median forecasts (see Abarbanell, 1991; Freeman and Tse, 1992; Lustgarten and Mande, 1998; Ashbaugh and Pincus, 2001), these forecasts may be biased (Hayes and Levine, 2000). Different specifications of the DCF valuation model are investigated, including extending the explicit growth phase through to both years $t+10$ and $t+13$ by making use of either analyst long-term growth $(g L T)$ forecasts or plowback principles with reinvestment rates commencing at return on equity and fading towards cost of equity. Under the earnings yield model, we vary our controls specifically, including plowback-based growth estimates (i.e. product of return on equity and retention); the dividend payout ratio as an alternate measure of growth potential; size and value factor loadings ${ }^{8}$; and total assets as an alternative proxy for size.

\section{Data}

We analyse stocks that are constituents of the Standard and Poor's/ Australian Securities Exchange (S\&P/ASX) 300 Index. Our sample is restricted to between fiscal years 1996-1997 and 2010-2011 (July 1996-June 2011) due to

\footnotetext{
${ }^{8}$ To proxy for the size and value factors, we apply the Faff $(2001,2003,2004)$ replication technique by imitating the Fama and French (1993) factors with commercially available equity style indices generated by Standard and Poors (S\&P). Factor loadings are estimated relative to these proxies using data over the preceding 48 months.
} 
data availability issues related to consensus forecasts. Our sample excludes stocks primarily operating as REITs, consistent with the literature (Fama and French, 1996, 2002; Daniel and Titman, 1997). Further, distributions from Australian REITs contain multiple components with differing tax status. The inclusion of these distributions might interfere with the identification of the effects solely induced by the presence of imputation credits.

We create our samples for analysis by initially drawing data for all available stocks. We extract data once per fiscal year for the month when each stock goes ex-dividend following the end of its previous financial year. This facilitates the best possible alignment between availability of recent accounting information including franking levels, analyst forecasts, share prices and the timing of future dividend payments. Use of one observation per year for each stock increases the likelihood of independent observations. ${ }^{9}$ We then remove observations for a stock in any period that contained missing or suspect and probably erroneous data, in the manner described below. This process results in varying data sets across tests due to differing availability of the various data series: we attempted to maximise the number of available observations for each test, rather than build a consistent but smaller sample.

Initially, we filter out observations where data were absent for either imputation or consensus forecasts through period $t+3$; consensus EPS forecasts for period $t+3$ was $<0$; consensus EPS forecasts for period $t+3$ or the sum of consensus DPS forecast for period $t+1$ and $t+2$ exceeded the share price at period $t$; or there was insufficient prior return data to facilitate beta estimation. This created a working sample of 3100 individual data points. This sample consisted of 468 unique stocks, with the number of stocks increasing from 98 in fiscal year 1996-1997 to 288 in 2010-2011. The DCF analysis was initially conducted on this sample and then extended to narrower samples, which involved removing observations with large differences between the DCF valuation and share price. ${ }^{10}$ The sample for the earnings yield analysis was formed by commencing with the working sample and then removing observations where data were unavailable for any of the explanatory variables; 1 -year forward earnings were negative; the dividend yield exceeded 33.3 per cent; or consensus earnings growth seemed extreme. ${ }^{11}$ The sample

\footnotetext{
9 More regular observations may not be independent, to the extent that cash-flow estimates may be unchanged.

${ }^{10}$ Filtering was performed with reference to $P_{k_{t}} /\left[P V\left(D_{k_{t}}\right)+P V\left(I C_{k_{t}}\right)\right]$ at two levels. First, observations with values $<0.2$ and $>5.0$ were removed, resulting in sample of 2946 . Second, observations with values $<0.4$ and $>2.5$ were removed, resulting in sample of 2565 .

${ }^{11}$ For consensus EPS growth forecasts between year $t+1$ and year $t+3$, observations with the highest and lowest 0.5 per cent growth rates were removed (cut-offs of -42.3 and +200 per cent per annum). For consensus long-term earning growth, observations with growth rates $>50$ per cent and $<50$ per cent were removed.
} 
involves 1783 observations when all variables of interest are included and 2782 observations where $g L T$ and leverage $(D / A)$ were excluded from the model.

Information on imputation credits, dividend amounts and ex-dividend dates are sourced from the Securities Industry Research Centre of Asia-Pacific (SIRCA) database. Monthly dividend and ICY are calculated as the amount of dividends and imputation credits received in a month, scaled by the price of the stock in the preceding month. The sample consists of stocks that distribute fully franked, partially franked and unfranked dividends. Figure 1 plots the proportions.

Other stock-specific data and accounting information are sourced from Thomson Reuters Datastream. This includes monthly stock prices, market capitalisation, book values, total debt and total assets. Consensus analyst forecast data, including earnings, dividends and earnings growth forecasts, are retrieved from I/B/E/S through Thomson Reuters Datastream. Monthly yields on 30-day bank-accepted bills are gathered from the Reserve Bank of Australia as proxy for the risk-free rate. Table 1 presents some descriptive statistics. A notable feature is the existence of present value estimates that differ substantially from share prices in the tails, which could reflect either extreme analyst expectations or data errors. This motivates investigating the sensitivity to outliers by examining results based on subsamples that have been filtered for the more extreme values of $P_{k_{t}} /\left[P V\left(D_{k_{t}}\right)+P V\left(I C_{k_{t}}\right)\right]$.

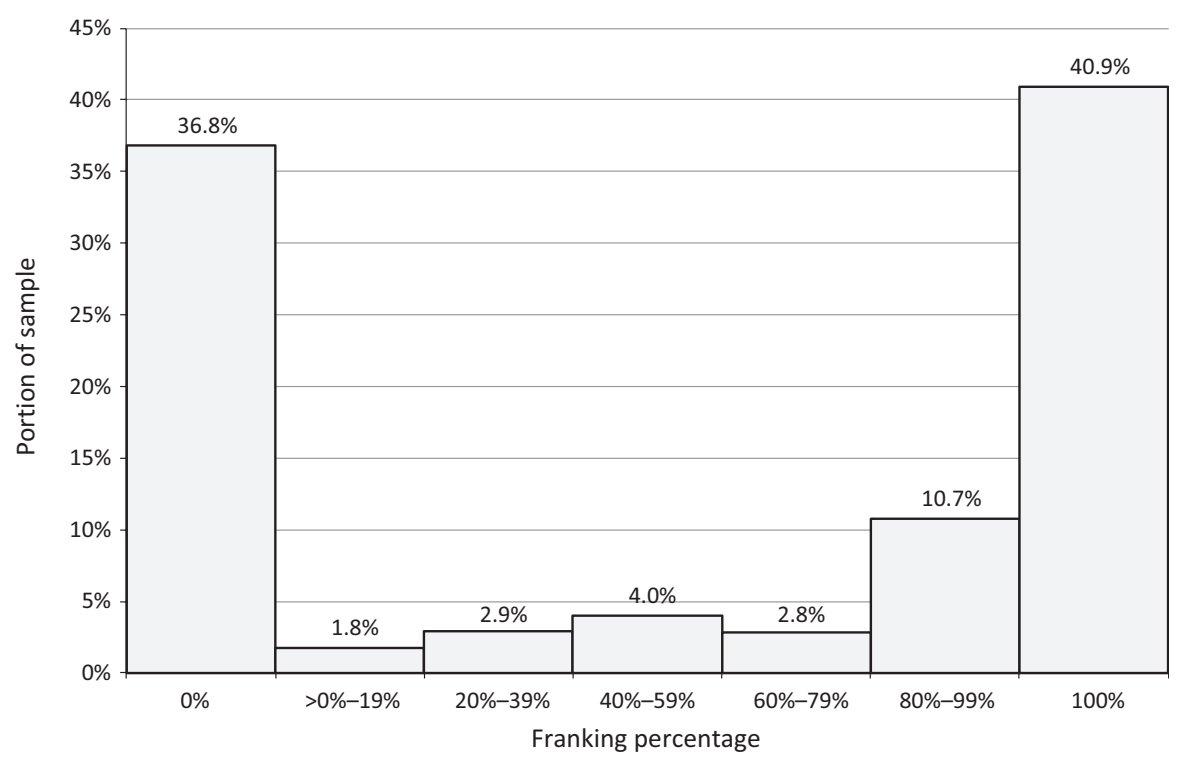

Figure 1 Distribution of franking percentage. This chart depicts the distribution of franking levels for all dividends distributed by stocks in our sample between July 1996 and June 2011. 


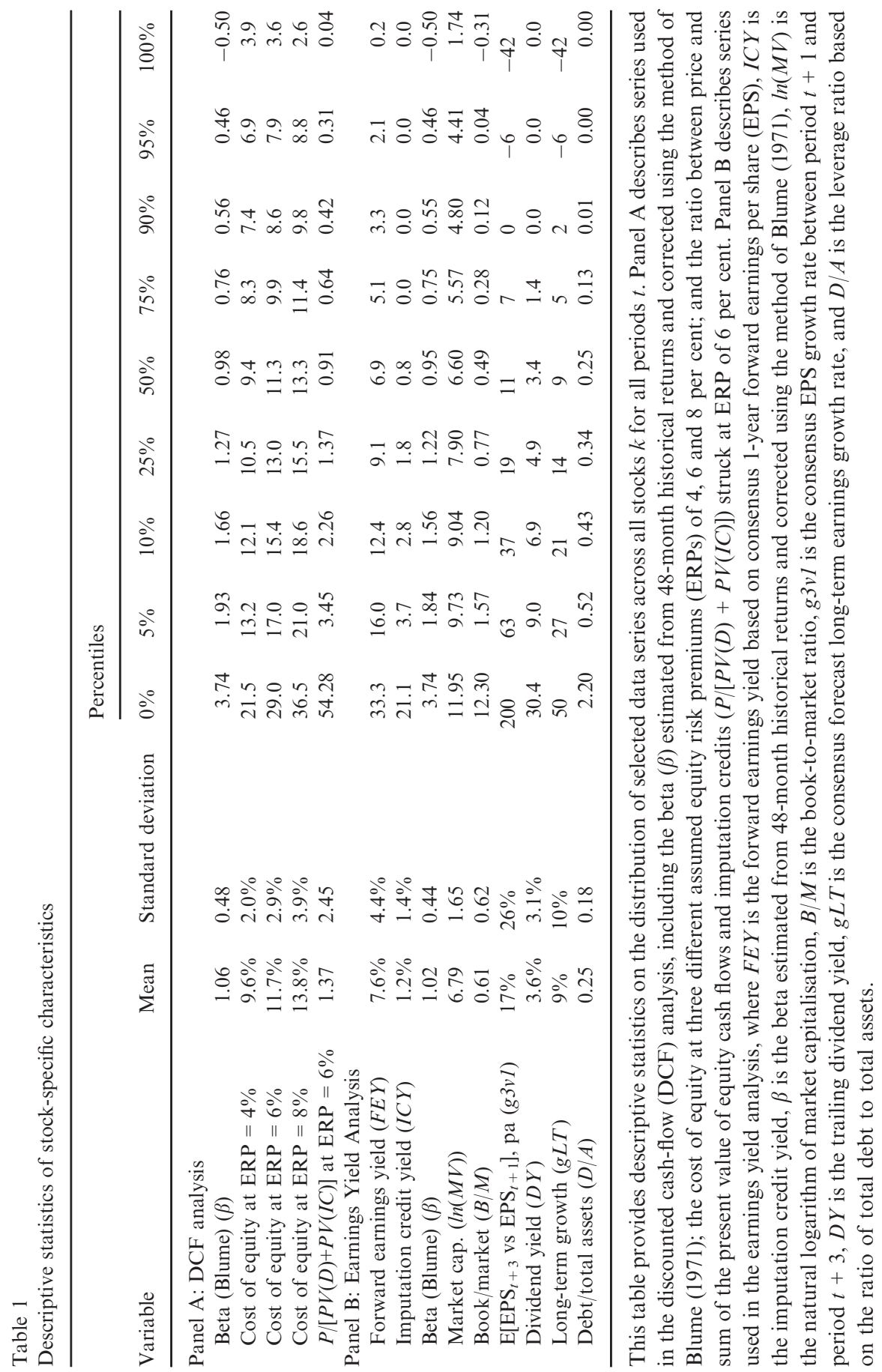


We evaluate the potential for multicollinearity by calculating a crosscorrelation of variables. The correlation between $P V\left(D_{k_{t}}\right)$ and $P V\left(I C_{k_{t}}\right)$ for ERP of 6 per cent is 0.83 across the full DCF sample and 0.87 for the subsample excluding resources. A high correlation is to be expected, given that the data are in level terms. An alternative guide is the correlation between the variables scaled by price (i.e. $P V\left(D_{k_{t}}\right) / P_{k_{t}}$ and $P V\left(I C_{k_{t}}\right) / P_{k_{t}}$, which stands at 0.33 for the full sample. Correlations for variables used under the earnings yields model per Equation (7) appear in Table 2. While we do not observe evidence of excessive collinearity across most of the explanatory variables, the strong correlation of 0.57 between $D Y$ and ICYs is noteworthy.

\section{Results}

We report and discuss the results under the DCF model in Section 5.1. and then the earnings yield analysis in Section 5.2. Robustness testing is addressed in Section 5.3.

Table 2

Correlation matrix of key explanatory variables

\begin{tabular}{|c|c|c|c|c|c|c|c|c|c|}
\hline & $E Y$ & $I C Y$ & $\beta$ & $\operatorname{Ln}(M V)$ & $B / M$ & $g 3 v 1$ & $D Y$ & $g L T$ & $D / A$ \\
\hline $\begin{array}{l}\text { Forward earnings } \\
\text { yield }(F E Y)\end{array}$ & 1.00 & & & & & & & & \\
\hline $\begin{array}{l}\text { Imputation credit } \\
\text { yield }(I C Y)\end{array}$ & 0.28 & 1.00 & & & & & & & \\
\hline Beta (Blume) $(B)$ & 0.08 & -0.16 & 1.00 & & & & & & \\
\hline Market cap. $(\ln (M V))$ & -0.32 & -0.02 & -0.06 & 1.00 & & & & & \\
\hline Book/market $(B / M)$ & 0.51 & 0.09 & 0.09 & -0.27 & 1.00 & & & & \\
\hline $\begin{array}{l}\mathrm{E}\left[\mathrm{EPS}_{t+3} \mathrm{vs} \mathrm{EPS}_{t+1}\right] \\
\text { pa }(g 3 v 1)\end{array}$ & -0.29 & -0.18 & 0.19 & -0.12 & 0.01 & 1.00 & & & \\
\hline Dividend yield $(D Y)$ & 0.38 & 0.57 & -0.24 & -0.04 & 0.19 & -0.26 & 1.00 & & \\
\hline $\begin{array}{l}\text { Long-term } \\
\text { growth }(g L T)\end{array}$ & -0.21 & -0.16 & 0.01 & 0.02 & -0.13 & 0.23 & -0.21 & 1.00 & \\
\hline $\begin{array}{l}\text { Debt/total } \\
\text { assets }(D / A)\end{array}$ & -0.02 & 0.01 & -0.13 & 0.15 & 0.01 & 0.09 & 0.09 & 0.05 & 1.00 \\
\hline
\end{tabular}

This table presents the correlation coefficients for each pair of key explanatory variables employed under the earnings yield analysis. The correlation coefficients are estimated for all available observations in our final sample across all stocks $k$ for all periods $t$. FEY is the forward earnings yield based on consensus 1-year forward earnings per share (EPS), ICY is the imputation credit yield, $\beta$ is the beta estimated from 48-month historical returns and corrected using the method of Blume (1971), $\ln (M V)$ is the natural logarithm of market capitalisation, $B / M$ is the book-to-market ratio, $g 3 v 1$ is the consensus EPS growth rate between period $t+1$ and period $t+3, D Y$ is the trailing dividend yield, $g L T$ is the consensus forecast long-term earnings growth rate, and $D / A$ is the leverage ratio based on the ratio of total debt to total assets. 


\subsection{Analysis of prices under a DCF valuation model}

Our DCF analysis proceeds as follows. We initially regress $P_{k_{t}}$ on $P V\left(D_{k_{t}}\right)$ only and then on both $P V\left(D_{k_{t}}\right)$ and $P V\left(I C_{k_{t}}\right)$ for our full sample for ERPs ranging from 4 to 8 per cent. We then conduct further analysis on subsamples that have been filtered for observations with a large difference between the observed share price and estimated present values at two cut-off levels, encapsulating $P_{k_{t}} /\left[P V\left(D_{k_{t}}\right)+P V\left(I C_{k_{t}}\right)\right]$ in the range of [0.2-5] and [0.4-2.5], respectively. As it is difficult to tell whether the difference between price and estimated present value is the consequence of data errors or extreme analyst expectations, this tiered approach allows us to establish that the main results are not overly sensitive to outliers. ${ }^{12}$ Given that there was minimal difference in the results for the $P_{k_{t}} /\left[P V\left(D_{k_{t}}\right)+P V\left(I C_{k_{t}}\right)\right]$ ranges of [0.2-5.0] and [0.4-2.5], we focus on the former. The analysis is then extended to portfolio sorts. We report some results for the subsample excluding resource stocks in this section, but discuss them under robustness testing.

Our initial focus is the slope coefficients ${ }^{13}$ on $P V\left(D_{k_{t}}\right)$ and $P V\left(I C_{k_{t}}\right)$, which provide estimates of the extent to which $\$ 1.00$ of present value in dividends and imputation credits are, respectively, valued in the cross-section. Correct specification under our DCF model requires a coefficient of 1.00 on $P V\left(D_{k_{t}}\right)$, thus implying that dividends are fully accounted for with 1 variation equating to $\$ 1$ variation in stock prices. Results where the coefficient on $P V\left(D_{k_{t}}\right)$ is nearest 1.00 may be considered preferred, which typically occurs at an ERP of 5-6 per cent. This implies that the marginal investor's ex ante ERP averaged near 6 per cent over the sample period, conditional on the consensus dividend and earnings projections. An ERP of 6 per cent seems plausible and is broadly consistent with the findings of Brailsford et al. (2008) and Fernandez et al. (2011). We emphasise estimates struck at an assumed ERP of 6 per cent when extending the analysis.

Table 3 presents the regression results. Estimates from the model including both $P V\left(D_{k_{t}}\right)$ and $P V\left(I C_{k_{t}}\right)$ give the initial impression that imputation credits are partially valued by the market. Results under both the full sample (Panel A) and the sample filtered for extreme values of price-to-present value (Panel B) suggest that imputation credits are valued at near $\$ 0.30$ per dollar on average

\footnotetext{
${ }^{12}$ Regressions using the full sample generated incongruous coefficients at higher ERPs, most notably coefficients of +1.456 on $P V\left(D_{k_{t}}\right)$ and -2.410 on $P V\left(I C_{k_{t}}\right)$ at $\mathrm{ERP}=8$ per cent. These results can be traced to some higher magnitude beta estimates that give rise to valuation outliers when beta is multiplied by higher ERPs. The filtered sample is less exposed to these outliers and hence delivers monotonic changes in regression coefficients as ERP increases. Importantly, the results for ERP $=6$ per cent are broadly consistent between the full and the filtered samples.

${ }^{13}$ The regression constant is of secondary interest. It acts as scaling variable with respect to level and may be influenced by aspects such as systemic analyst forecast errors.
} 
Table 3

Key results for discounted cash-flow (DCF) analysis

\begin{tabular}{|c|c|c|c|c|c|c|}
\hline & \multirow[b]{2}{*}{ Obs. } & \multicolumn{5}{|c|}{ Regression coefficients } \\
\hline & & $\begin{array}{l}\text { Constant } \\
\text { ( } t \text {-stat) }\end{array}$ & $P V\left(D_{k_{t}}\right)(t$-stat $)$ & $P V\left(I C_{k_{t}}\right)(t$-stat $)$ & $R^{2}$ & Adj. $R^{2}$ \\
\hline \multicolumn{7}{|c|}{ Panel A: full sample } \\
\hline \multicolumn{7}{|c|}{$P V\left(D_{k}\right)$ only } \\
\hline $\mathrm{ERP}=4 \%$ & 3100 & $0.644(3.82) * * *$ & $0.825(10.13)^{* * *}$ & & $65.7 \%$ & $62.2 \%$ \\
\hline $\mathrm{ERP}=5 \%$ & 3100 & $0.656(3.89) * * *$ & $0.945(11.58)^{* * *}$ & & $65.3 \%$ & $61.8 \%$ \\
\hline $\mathrm{ERP}=6 \%$ & 3100 & $0.687(4.01)^{* * *}$ & $1.058(11.84)^{* * *}$ & & $64.6 \%$ & $61.0 \%$ \\
\hline $\mathrm{ERP}=7 \%$ & 3100 & $0.837(3.51)^{* * *}$ & $1.144(11.54)^{* * *}$ & & $62.8 \%$ & $59.0 \%$ \\
\hline $\mathrm{ERP}=8 \%$ & 3100 & $3.362(2.47)^{* * *}$ & $0.663(1.98)^{* *}$ & & $38.3 \%$ & $32.0 \%$ \\
\hline \multicolumn{7}{|c|}{$P V\left(D_{k_{s}}\right)$ and $P V\left(I C_{k_{t}}\right)$} \\
\hline $\mathrm{ERP}=4 \%$ & 3100 & $0.711(3.68)^{* * *}$ & $0.745(7.54)^{* * *}$ & $0.332(2.79)^{* * *}$ & $65.9 \%$ & $62.4 \%$ \\
\hline $\mathrm{ERP}=5 \%$ & 3100 & $0.707(3.92)^{* * *}$ & $0.864(7.85)^{* * *}$ & $0.337(2.25)^{* *}$ & $65.5 \%$ & $61.9 \%$ \\
\hline $\mathrm{ERP}=6 \%$ & 3100 & $0.739(4.07)^{* * *}$ & $0.984(8.04)^{* * *}$ & $0.300(1.46)$ & $64.7 \%$ & $61.1 \%$ \\
\hline $\mathrm{ERP}=7 \%$ & 3100 & $0.854(3.85)^{* * *}$ & $1.120(8.19)^{* * *}$ & $0.096(0.30)$ & $62.8 \%$ & $59.0 \%$ \\
\hline $\mathrm{ERP}=8 \%$ & 3100 & $2.196(4.07)^{* * *}$ & $1.458(7.98)^{* * *}$ & $-2.410(-2.52)^{* * *}$ & $45.5 \%$ & $39.9 \%$ \\
\hline \multicolumn{7}{|c|}{ Excluding resources } \\
\hline $\mathrm{ERP}=6 \%$ & 2382 & $0.771(4.28)^{* * *}$ & $0.873(13.91)^{* * *}$ & $0.594(2.97)^{* * *}$ & $64.7 \%$ & $61.4 \%$ \\
\hline $\mathrm{ERP}=7 \%$ & 2382 & $0.940(3.94)^{* * *}$ & $0.993(12.83)^{* * *}$ & $0.403(1.17)$ & $62.2 \%$ & $58.6 \%$ \\
\hline \multicolumn{7}{|c|}{ Panel B: filtered extreme $\mathrm{P} / \mathrm{PV}$} \\
\hline \multicolumn{7}{|c|}{$\begin{array}{l}P_{k_{t}} /\left[P V\left(D_{k_{t}}\right)+P V\left(I C_{k_{t}}\right)\right]=[>0.2,<5] \\
P V\left(D_{k}\right) \text { only }\end{array}$} \\
\hline $\mathrm{ERP}=4 \%$ & 2946 & $0.236(1.64)^{*}$ & $0.869(11.58)^{* * *}$ & & $77.6 \%$ & $75.3 \%$ \\
\hline $\mathrm{ERP}=5 \%$ & 2946 & $0.218(1.63)^{*}$ & $1.000(12.54)^{* * *}$ & & $77.4 \%$ & $75.1 \%$ \\
\hline $\mathrm{ERP}=6 \%$ & 2946 & $0.219(1.64)^{*}$ & $1.129(13.33)^{* * *}$ & & $77.1 \%$ & $74.7 \%$ \\
\hline $\mathrm{ERP}=7 \%$ & 2946 & $0.233(1.69)^{*}$ & $1.255(13.19)^{* * *}$ & & $76.6 \%$ & $74.2 \%$ \\
\hline $\mathrm{ERP}=8 \%$ & 2946 & $0.260(1.74)^{*}$ & $1.378(13.45)^{* * *}$ & & $76.0 \%$ & $73.5 \%$ \\
\hline \multicolumn{7}{|c|}{$P V\left(D_{k_{t}}\right)$ and $P V\left(I C_{k_{t}}\right)$} \\
\hline $\mathrm{ERP}=4 \%$ & 2946 & $0.280(1.79)^{*}$ & $0.809(9.63)^{* * *}$ & $0.251(2.68)^{* * *}$ & $77.8 \%$ & $75.5 \%$ \\
\hline $\mathrm{ERP}=5 \%$ & 2946 & $0.261(1.66)^{*}$ & $0.934(9.26)^{* * *}$ & $0.275(2.21)^{* *}$ & $77.5 \%$ & $75.2 \%$ \\
\hline $\mathrm{ERP}=6 \%$ & 2946 & $0.261(1.68)^{*}$ & $1.056(10.02)^{* * *}$ & $0.300(2.00)^{* *}$ & $77.2 \%$ & $74.8 \%$ \\
\hline $\mathrm{ERP}=7 \%$ & 2946 & $0.274(1.71)^{*}$ & $1.176(9.88)^{* * *}$ & $0.324(1.73)^{*}$ & $77.0 \%$ & $74.3 \%$ \\
\hline $\mathrm{ERP}=8 \%$ & 2946 & $0.299(1.78)^{*}$ & $1.295(9.68)^{* * *}$ & $0.338(1.49)^{*}$ & $76.1 \%$ & $73.6 \%$ \\
\hline \multicolumn{7}{|c|}{ Excluding resources } \\
\hline $\mathrm{ERP}=6 \%$ & 2301 & $0.388(2.97)^{* * *}$ & $0.887(12.87)^{* * *}$ & $0.697(4.18)^{* * *}$ & $78.1 \%$ & $75.9 \%$ \\
\hline $\mathrm{ERP}=7 \%$ & 2301 & $0.403(3.02) * * *$ & $0.981(12.32)^{* * *}$ & $0.782(3.86)^{* * *}$ & $77.6 \%$ & $75.5 \%$ \\
\hline
\end{tabular}

Panel A reports results for the full DCF sample. Panel B reports results for the subsample excluding observations where the ratio $P_{k_{t}} /\left[P V\left(D_{k_{t}}\right)+P V\left(I C_{k_{t}}\right)\right]$ is $<0.2$ or exceeds 5.0. All regressions include fiscal year fixed effects. $t$-Statistics are reported in brackets and are computed using robust standard errors clustered by both fiscal year and firm (see Petersen, 2009). *, ** and $* * *$ denote significance at 10,5 and 1 per cent. This table reports selected key results for regressions of stock prices $\left(P_{k_{t}}\right)$ on the present value of dividends $P V\left(D_{k_{t}}\right)$ and imputation credits $\left(P V\left(I C_{k_{t}}\right)\right)$, formed under a version of the Gordon and Gordon (1997) DCF valuation model. The DCF model is applied using 3 years of median consensus analyst forecasts, with future cash flows discounted at the relevant CAPM cost of equity calculated using treasury bill rates, estimated betas and ex ante equity risk premium (ERP) assumptions ranging from 4 to 8 per cent. The general form of the regression is as follows:

$$
P_{k_{t}}=\beta_{0}+\beta_{1} P V\left(D_{k_{t}}\right)+\beta_{2} P V\left(I C_{k_{t}}\right)+\tilde{\varepsilon}_{k_{t}}
$$


over the full period, conditional on $P V\left(D_{k_{t}}\right)$ being valued at around $\$ 1.00$. However, the coefficients on $P V\left(I C_{k_{t}}\right)$ are statistically significant only under the filtered sample. The increase in $R$-squared relative to the regressions on $P V\left(D_{k_{t}}\right)$ alone is modest, at around +0.1 per cent. While a partial F-statistic (significant at the 1 per cent level) indicates that the expanded model is preferred from a statistical perspective, clearly the addition to explanatory power is minimal in economic terms. We also note that the coefficients on $P V\left(D_{k_{t}}\right)$ change by around -0.07 upon expanding the model by including $P V\left(I C_{k_{t}}\right)$ Given that the average value of $P V\left(I C_{k_{t}}\right)$ is around 16-22 per cent ${ }^{14}$ of the average value of $P V\left(D_{k_{t}}\right)$, the coefficient of around 0.30 on $P V\left(I C_{k_{t}}\right)$ appears to emerge in large part as a reallocation of the explanatory power, which had initially resided in $P V\left(D_{k_{t}}\right)$. These observations combine with concerns over multicollinearity between the present value of dividends $P V\left(D_{k_{t}}\right)$ and imputation credits $P V\left(I C_{k_{t}}\right)$ to cast some doubt over the economic content of the expanded model.

Portfolio sorts provide an alternative method to evaluate the relation between imputation credits and share prices under the DCF model. The aim is evaluate whether the magnitude of imputation credits is associated with observed pricing errors under a DCF model based around only the present value of equity cash flows, $P V\left(D_{k_{t}}\right)$. We conduct two sets of sorts: a single-sort by imputation credit yield $(I C Y)$ alone and a double-sort by dividend yield $(D Y)$ and $I C Y$. We focus on the ratio of price-to-present value of equity cash flows, $P_{k_{t}} / P V\left(D_{k_{t}}\right)$. The concept is that if $P V\left(I C_{k_{t}}\right)$ is valued by the marginal investor and hence reflected in share prices, then the pattern of $P_{k_{t}} / P V\left(D_{k_{t}}\right)$ across portfolios will reflect a missing variable. As this missing variable is highly correlated with $I C Y,{ }^{15}$ the ratio should rise across portfolios sorted by $I C Y$. Panel A of Table 4 reports the median ${ }^{16} P_{k_{t}} / P V\left(D_{k_{t}}\right)$ ratios for portfolios sorted by $I C Y$. It is immediately obvious that under a single-sort by $I C Y$ alone that the $P_{k_{t}} / P V\left(D_{k_{t}}\right)$ ratio trends the wrong way. That is, price declines relative to present value of equity cash flows as $I C Y$ increases, most notably for franked stocks. It is possible that this result may reflect other missing factors that could be correlated with $I C Y$. The likely candidates are risks not fully accounted for in the discount rate used to estimate net present value, and influences related to the value effect reflected in the value factor of Fama and French (1993). Hence, we conduct a double-sort, where $D Y$ is included as a sorting variable on the basis that it may control for such missing factors. The process involves initially

\footnotetext{
14 Estimate varies with sample and method of calculation.

${ }^{15}$ The assumption is that observed $I C Y$ is a good proxy for the level of expected future imputation credits.

${ }^{16}$ Portfolio means generate similar results. We also tried sorting within fiscal years and then aggregating, to ensure that sorts were not merely capturing variations through time. This made minimal difference to the results.
} 


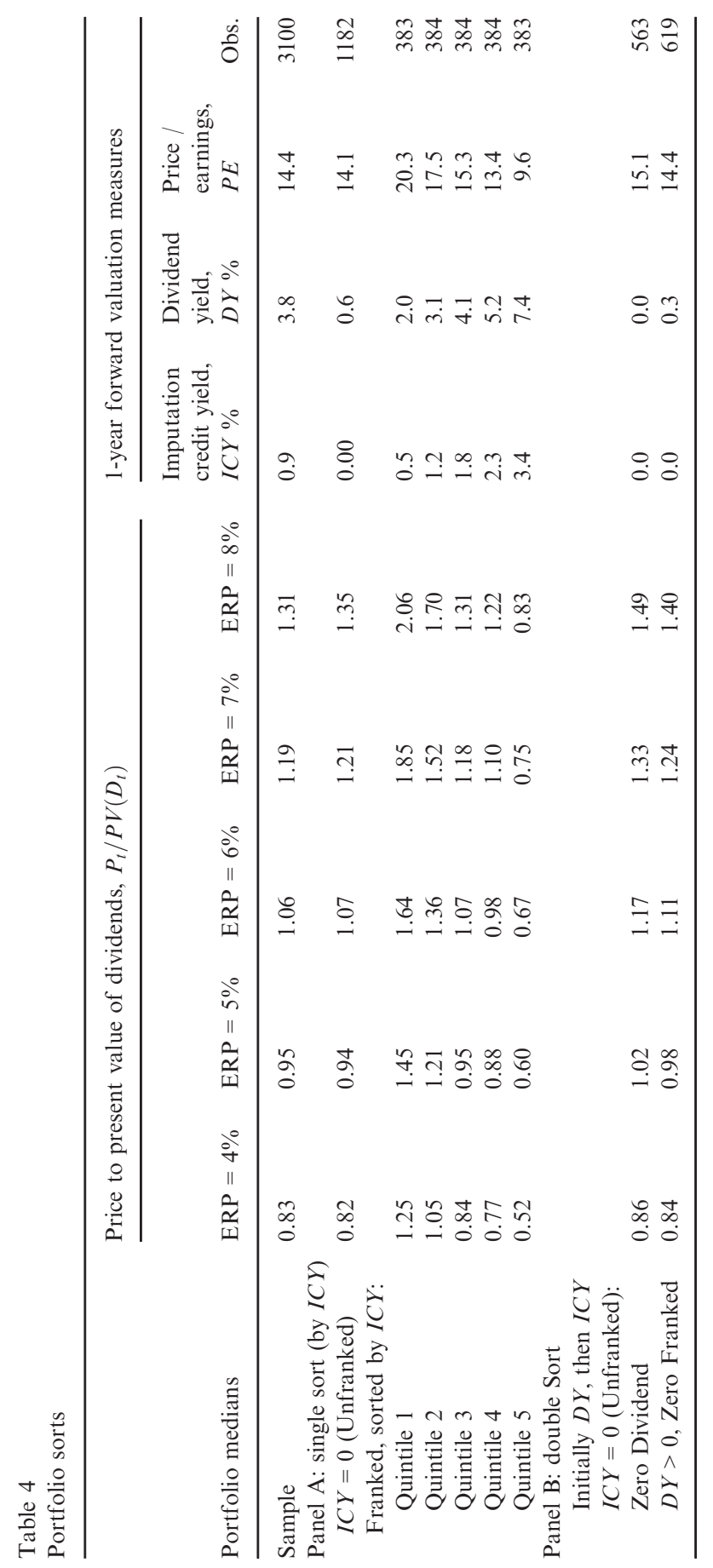




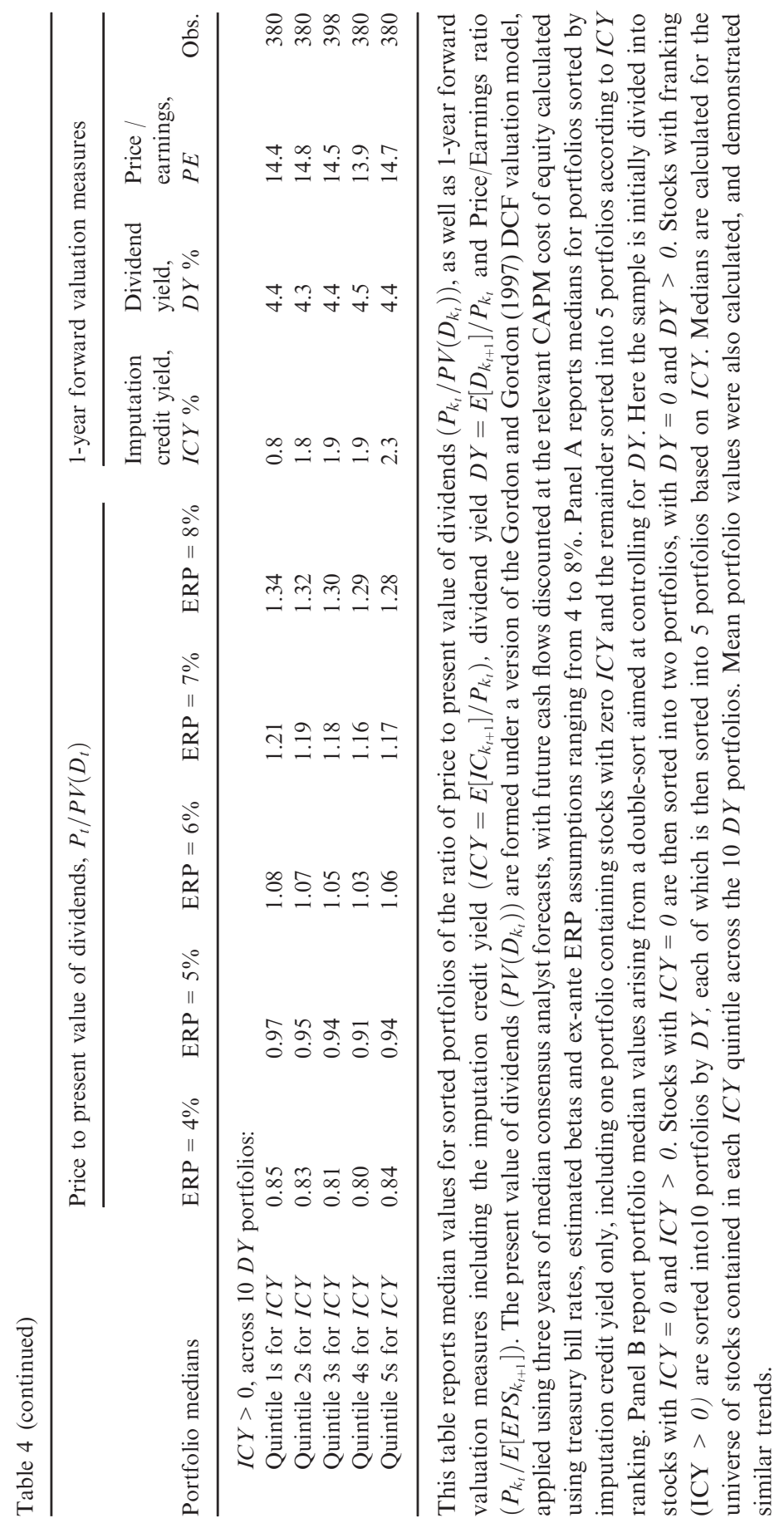


dividing the universe into unfranked $(I C Y=0)$ and franked stocks $(I C Y>0)$. Unfranked stocks are then sorted into two portfolios, those with $D Y=0$ and those with $D Y>0$. Franked stocks are sorted into 10 portfolios by $D Y$, each of which is then sorted into five portfolios based on ICY. Panel B of Table 5 reports the median $P_{k_{t}} / P V\left(D_{k_{t}}\right)$ ratios for the universe of stocks contained in each ICY quintile across the $10 \mathrm{DY}$ portfolios. Under this procedure, the relation between $I C Y$ and $P_{k_{t}} / P V\left(D_{k_{t}}\right)$ largely disappears. The $P_{k_{t}} / P V\left(D_{k_{t}}\right)$ ratio is essentially flat across the 5 quintiles for franked stocks, although it is highest for unfranked stocks. ${ }^{17}$ In any event, no indication emerges that stocks trade at larger premiums to the present value of equity cash flows as imputation credits increase.

The analysis presented in this section provides mixed and inconclusive evidence that including a term for the present value of imputation credits in a DCF valuation model assists in the ability to explain the distribution of share prices. The present value of imputation credits attracts a positive coefficient under a multiple regression. However, this coefficient needs to be viewed with caution due to multicollinearity with the present value of equity cash flows, and including imputation credits adds only an economically small amount to the overall ability to explain the distribution of share prices. Portfolio sorts find that the pricing errors under a basic model including only the net present value of equity cash flows fail to follow a pattern that suggests imputation credits are an important missing variable. Overall, the results seem to indicate that incorporating imputation credits adds little relative to a basic DCF model in which they are ignored.

\subsection{Imputation credits and earnings yields}

The analysis of forward earnings yields ( FEY) proceeds as follows. We initially run regressions on the sample where all variables are available. This analysis ascertains that the long-term earnings growth $(g L T)$ and leverage $(D /$ $A$ ) variables are not significant. We then focus on the (larger) 'core' sample excluding these control variables. All other control variables are significant at the 1 per cent level and have the expected sign. Coefficients are positive for beta (higher FEY with higher systematic risk); negative for market capitalisation (higher $F E Y$ for smaller stocks); positive for market/book while negative on expected earnings growth between $t+1$ and $t+3$ (higher $F E Y$ with lower growth prospects); and positive on $D Y$. The latter may be acting as a proxy for discount rate effects or growth expectations not captured by other control variables. Following on from the DCF analysis, we examine marginal effects by reporting comparison regressions where $I C Y$ is excluded as an explanatory

\footnotetext{
${ }^{17}$ Although higher $P_{k_{t}} / P V\left(D_{k_{t}}\right)$ ratios for unfranked stocks is contrary to what might be expected if imputation credits were valued, it could easily be attributable to unobserved variables for this subsample.
} 


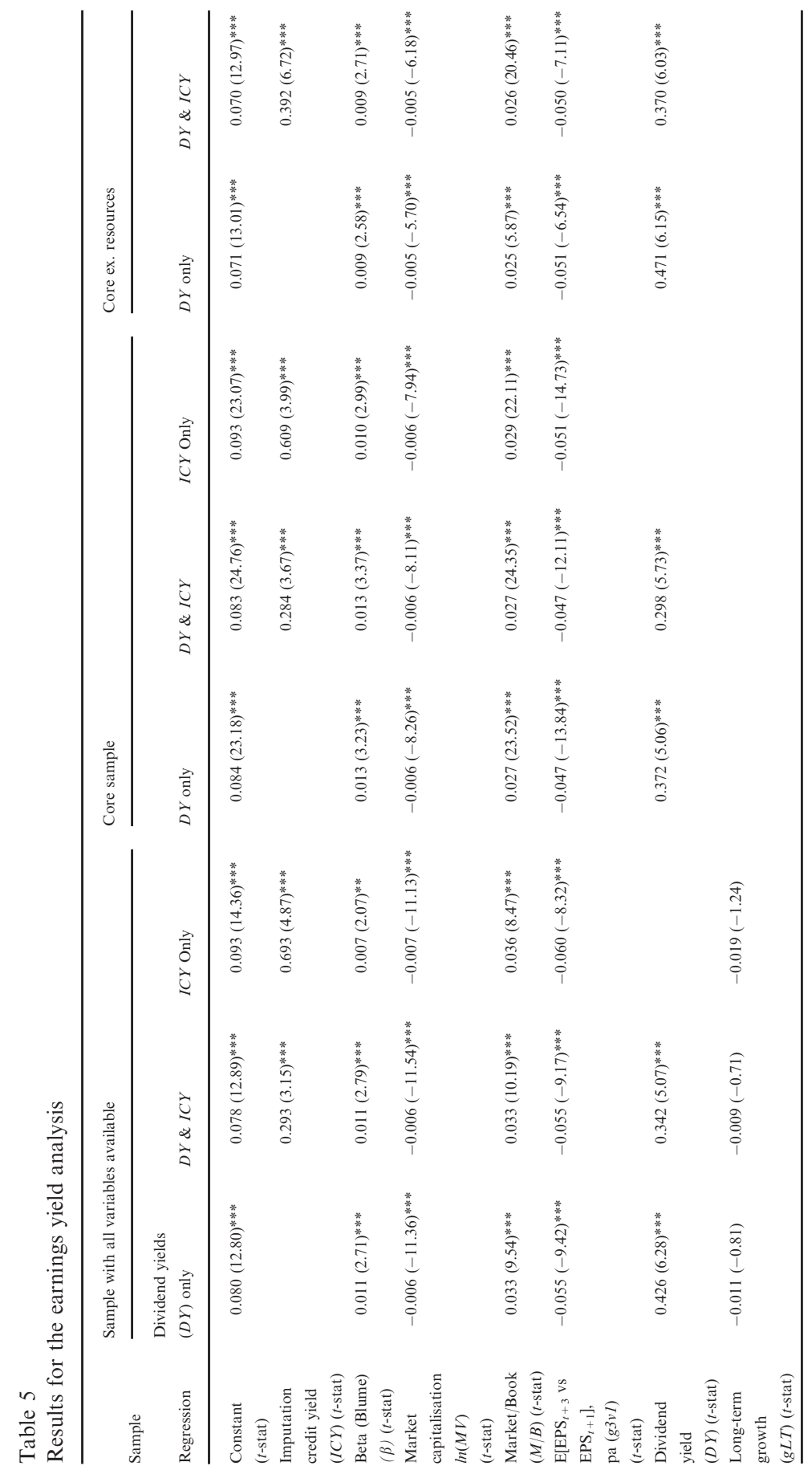




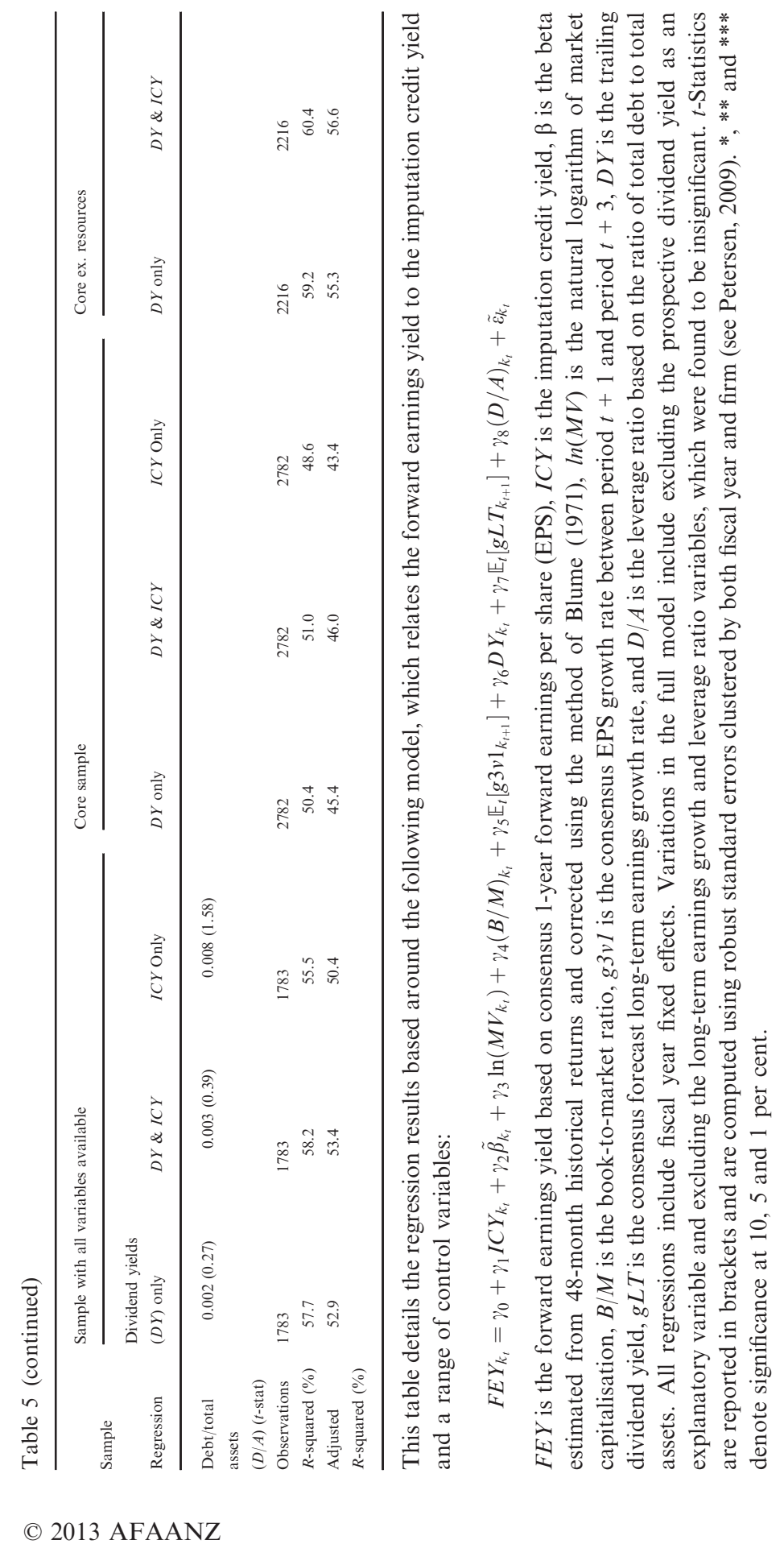


variable. We also refer back to the portfolio sorts reported in Table 4. Some results are reported for the subsample excluding resource stocks in this section, which will be discussed under robustness testing.

Results are reported in Table 5. The estimated coefficients on ICY with all available control variables included are significantly positive at around $0.29 .^{18}$ The finding that a higher $I C Y$ is associated with a higher FEY and therefore lower share prices is the opposite of what would be expected if imputation credits were valued by the marginal investor. Further, there is evidence that imputation credits make a larger marginal contribution to explaining the distribution of FEY than they did under the DCF analysis, with $R$-squared increasing by $0.5-0.6$ per cent when $I C Y$ is included and the marginal $F$ statistic is significant at the 1 per cent level. Notably, the findings under the earnings yield regressions appear stronger, but stand in direct contradiction to the findings under the DCF model.

It remains possible that $I C Y$ could be acting as a proxy for missing variables correlated with FEY. The portfolio sorts reported in Table 4 provide some additional input on this issue. Median price/earnings ratios $(P E=1 / F E Y)$ for each portfolio are reported to the right of Table 4. Under the single-sort reported in Panel A, $P E$ declines with $I C Y$. This is consistent with the earnings yield regressions and contrary to what might be expected if imputation credits were valued in the market. However, the double-sorts reported under Panel B of Table 4 reveal no pattern for $P E$ across portfolios that vary by $I C Y$, but are initially sorted by $D Y$. Indeed, any relation between $I C Y$ and $F E Y$ disappears under these sorts. In summary, the earnings yield analysis suggests the conclusion that there is no evidence that imputation credits are associated with higher share prices ceterus paribas.

\subsection{Supplementary analysis and robustness tests}

Our first robustness test involves implementation of the Ohlson (1995) clean surplus accounting valuation. Table 6 reports the results. While the coefficients are not directly interpretable, evidence emerges that imputation credits make a contribution to explaining the distribution of share prices under this model. A significantly positive relation is observed between imputation credits and share prices when included in conjunction with earnings and book value variables. $R$ squared rises by a modest 0.4 per cent after imputation credits are included in the regression, which while small in economic terms is nevertheless statistically significant at 1 per cent based on a partial $F$-statistic. Nevertheless, multicollinearity also exists under this specification, with $I C_{k_{t}}$ having a correlation of 0.64 with $B V_{k_{t}}, 0.66$ with $E P S_{k_{t}}$ and 0.72 with $\mathbb{E}_{t}\left[E P S_{k_{t+1}}\right]$. We also note that the

\footnotetext{
${ }^{18}$ Interpretation of the coefficient on ICY is not straightforward, as it arises from a model of earnings yields. Nevertheless, it approximately translates to the value placed on of $\$ 1.00$ of imputation credits at the average $F E Y$.
} 


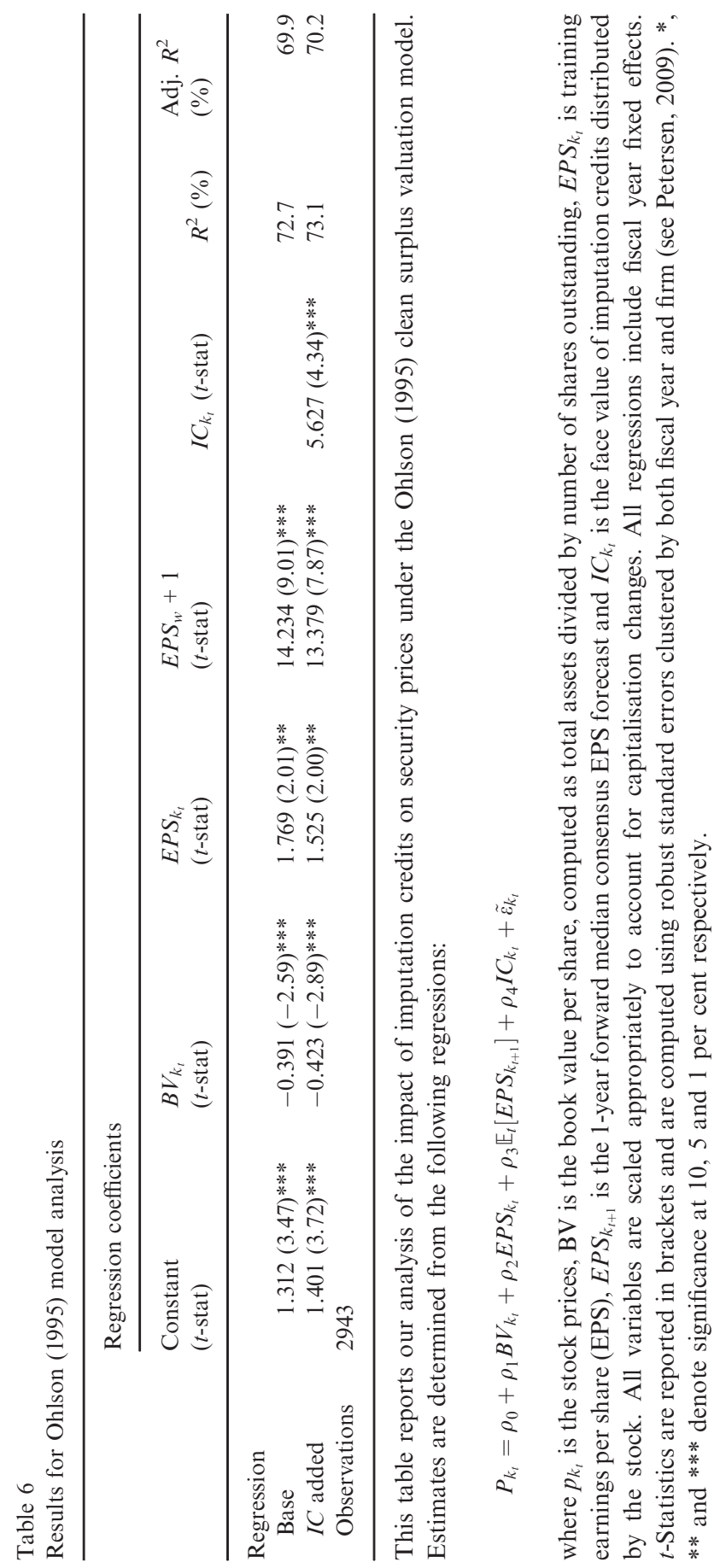


model of Ohlson (1995) is effectively a form of DCF model, which incorporates limited information on expected cash flows through use of only a single forecast earnings term, while making no adjustment for cost of capital differences across companies. By comparison, these aspects are accounted for under our preferred DCF model and the earnings yield analysis. It is hence possible that the Ohlson model results could reflect the failure to control for such aspects, to the extent they are correlated with imputation credits.

Our second set of robustness tests involves investigating various subsamples. The most notable findings relate to the sample excluding resource stocks, that is, 'industrials'. These results were reported earlier, but are discussed here. Analysis of this subsample generates a meaningful increase in the magnitude of the coefficient on $P V\left(I C_{k_{t}}\right)$ under the DCF model, where the coefficients on $P V\left(D_{k_{t}}\right)$ are closest to 1.00 at an ERP of 7 per cent (see Table 3). In this case, the coefficient on imputation credits is estimated at an (insignificant) 0.40 for the full sample and 0.78 for the filtered sample (significant at the 1 per cent level). However, multicollinearity is an even larger issue in this subsample, ${ }^{19}$ and again, the marginal effects are statistically significant, but economically modest. For the full sample, the increase in $R$-squared arising from including $P V\left(I C_{k_{t}}\right)$ is 0.4 per cent at ERP of 6 and 0.2 per cent at ERP of 7 per cent. Results under the filtered sample excluding resources are a bit stronger, with $R$ squared increasing by $0.6-0.7$ per cent. Nevertheless, the initial DCF results for this subsample give the impression that imputation credits may be more highly valued in the non-resource segment of the Australian market. Meanwhile, analysis of earnings yields for the subsample excluding resources generates a larger coefficient on ICY $(+0.392$ versus +0.284$)$ and a greater change in $R$-squared ( +1.2 per cent) relative to the full sample (see Table 5$)$. Overall, the results for the subsample excluding resources are similar in nature, yet amplified relative to the main findings.

Results from other subsamples were mixed and inconclusive and are discussed in general terms. With respect to the two tax regimes, our regressions generate inconsistent results. The coefficient on $P V\left(I C_{k_{t}}\right)$ increases post-June 2000 under the full sample, but decreases under the filtered sample. The subperiod analysis is hampered by a relatively small sample size of just over 500 observations pre-June 2000, reflecting lack of consensus analyst forecasts. Hence, we place little weight on the tax regime subsample findings. Estimates arising from year-by-year data and for the four broad industry sectors (consumer related, financials, other industrials, resources) are highly variable, ranging from negative values to over one. It seems that the additional noise inherent in smaller samples leads to inconsistent estimates. The subsample estimations serve to highlight the issue of multicollinearity between dividends and imputation credits, as higher coefficients on imputation credits are typically accompanied by lower coefficients on dividends and vice versa. For instance,

${ }^{19}$ The correlation between $P V\left(I C_{k_{t}}\right)$ and $P V\left(D_{k_{t}}\right)$ for this subsample is around 0.87 . 
the time series of yearly coefficient estimates for $P V\left(D_{k_{t}}\right)$ and $P V\left(I C_{k_{t}}\right)$ arising from the DCF analysis have a correlation of -0.82 . Similarly, yearly coefficients on $I C Y$ and $D Y$ under the earnings yield model have a correlation of -0.45 . Consequently, we emphasise the results from our overall sample, while noting that the sensitivity to sample selection reinforces the need for caution over the reliability of the coefficient estimates. Analysis of subsamples excluding stocks with market capitalisations below \$200 million and \$500 million generates estimates that vary marginally from those for the full sample, mainly in the direction of $P V\left(I C_{k_{t}}\right)$ becoming more meaningful under the DCF analysis. Nevertheless, the indication is that our findings are unlikely to have been impacted by unreliable data from small stocks.

Our third set of robustness checks involves using alternative explanatory variables. No substantial changes in findings are uncovered. The results under both the DCF and earnings yield analysis differ only marginally when the mean of consensus analyst forecasts is substituted for the medians. Different specifications of the DCF model generate more variable DCF valuation estimates and hence less reliable results than the original specification. We also re-estimate the earnings yield model under alternative specifications of the risk and growth controls. The coefficient on $I C Y$ varies only modestly upon including payout ratios or growth rates inferred from plowback principles as alternative growth proxies, or size and value factor loadings as additional risk proxies. ${ }^{20}$ The coefficient on $I C Y$ declines by a noticeable amount when the log of total assets is substituted for $\ln (M V)$ as a size proxy. However, this model is less satisfactory from both a theoretical and empirical perspective, as the specification can only be implemented with reduced sample size and meaningfully lower $R$-squared.

\section{Conclusion}

Knowledge of the market value attributed to imputation credits is important for estimating cost of capital, as well as 'fair value' stock prices. Estimates of the value of imputation credits generated by prior studies are mixed and subject to various shortcomings, including heavy focus on the pricing of dividend events; potential influence of traders and dividend arbitrageurs; various econometric issues; and lack of a sufficiently representative sample at times. Further, prior literature has not examined the prediction that the share prices of companies offering imputation credits should be higher to the extent those credits are valued by the marginal investor. We investigate this proposition, thus providing an alternative perspective that is subject to different estimation issues than encountered by other methods. Our study examines the relation between imputation credits and price levels under a DCF valuation model and through the analysis of earnings yields. In doing so, we adopt the perspective of

\footnotetext{
${ }^{20}$ While the coefficient on HML was found to be negative and significant, including it made little difference to the $I C Y$ coefficient estimates.
} 
a long-term 'buy-and-hold' investor. While our results are mixed, overall we fail to find clear evidence that imputation credits are capitalised into share prices. On the one hand, imputation credits are afforded a positive coefficient under the DCF and Ohlson (1995) model regressions. However, the regression estimates should be interpreted with caution in the presence of multicollinearity, and we observe only a small increment to explanatory power. On the other hand, no signs are detected that imputation credits influence pricing across portfolios sorted by imputation credit and $D Y$. There is also no evidence that the presence of imputation credits lowers earnings yields as might be expected if they were priced. When our own mixed results are combined with the finding of Lajbcygier and Wheatley (2012) that imputation credits do not lower realised returns, we conclude that there is little convincing evidence that imputation credits are priced from the perspective of long-term buy-and-hold investors.

We acknowledge the possible limitations of our analysis. It is clear that the availability of imputation credits across stocks is highly correlated with dividends, as well as valuation ratios such as $D Y$ and earnings yields. This gives rise to identification problems related to multicollinearity. Further, our analysis is exposed to the risk of missing variables that may be correlated with imputation credits or perhaps dividends. There are also limitations to our data. For instance, the consensus analyst forecasts utilised in our analysis could misrepresent the cash-flow expectations on which market prices are conditioned. Additionally, our overarching assumption that past distributions of imputation credits are the best predictor of future expected distributions may not be entirely appropriate.

While one can never totally rule out the possibility that results may stem from problems with method or data, we believe the more likely explanation is that imputation credits are not capitalised into Australian share prices. While imputation credits are often cited in the financial media and by equity analysts as being of value to shareholders and particularly superannuation funds, our findings highlight that this is not evidenced empirically. This sets up a paradox: if imputation credits are of value, why are they not reflected in prices? We posit that the most likely explanation is that imputation credits are not valued by the marginal investor (who in a small open economy such as Australia may be an international investor), for the simple reason that they do not receive the benefits accruing from imputation credits. This being the case, prices would then be lower and expected returns higher for stocks paying imputation credits than if they were priced. This is not necessarily bad news. In fact, for longerterm buy-and-hold investors, it is actually good news. If market returns are not lowered by the presence of imputation credits, then investors who benefit from dividend imputation may capture the full value of their imputation credits as a bonus or 'consumer surplus' over and above the market clearing rate of return - they can 'have their cake and eat it too'. For value investors, the news is even better. Imputation credits appear correlated with high dividend and earnings yields and, by inference, the value effect. This affords an opportunity to reap returns arising from both the value effect and the full value of any associated 
imputation credits. If there is a downside from imputation credits not having any significant impact on share prices and hence expected returns, it is that the cost of capital may be higher than otherwise. This can have a dampening influence on investment and value creation in the economy overall.

\section{References}

Abarbanell, J. S., 1991, Do analysts' earnings forecasts incorporate information in prior stock price changes?, Journal of Accounting and Economics 14, 147-165.

Ashbaugh, H., and M. Pincus, 2001, Domestic accounting standards, international accounting standards, and the predictability of earnings, Journal of Accounting Research 39, 417-434.

Ashton, D. J., 1991, Corporate financial policy, Journal of Business Finance and Accounting 18, 465-482.

Bali, R., and J. C. Francis, 2011, Trading volume around ex-dividend days, Applied Economics Letters 18, 769-772.

Bali, R., and G. L. Hite, 1998, Ex dividend day stock price behavior, Journal of Financial Economics 47, 127-159.

Beggs, D. J., and C. L. Skeels, 2006, Market arbitrage of cash dividends and franking credits, Economic Record 82, 239-252.

Bellamy, D. E., 1994, Evidence of imputation clienteles in the Australian equity market, Asia Pacific Journal of Management 11, 275-287.

Bellamy, D. E., and S. Gray, 2006, Using stock price changes to estimate the value of dividend franking credits, Paper presented at the AFAANZ Annual Conference (Melbourne).

Bettman, J. L., 2007, Australian evidence regarding the value-relevance of technical information, Australian Journal of Management 32, 57-71.

Bettman, J. L., S. J. Sault, and E. L. Schultz, 2009, Fundamental and technical analysis, Accounting and Finance 49, 21-36.

Blume, M. E., 1971, On the assessment of risk, The Journal of Finance 26, 1-10.

Boyd, J. H., and R. Jagannathan, 1994, Ex-dividend price behavior of common stocks, Review of Financial Studies 7, 711-741.

Brailsford, T., J. C. Handley, and K. Maheswaran, 2008, Re-examination of the historical equity risk premium in Australia, Accounting and Finance 48, 73-97.

Brooks, R., and R. W. Faff, 1997, A note on beta forecasting, Applied Economics Letters 4, 77-78.

Brown, P., and A. Clarke, 1993, The ex-dividend day behaviour of Australian share prices before and after dividend imputation, Australian Journal of Management 18, 1-40.

Brown, P., J. C. Y. How, and P. Verhoeven, 2008, The accuracy of analysts' dividend forecasts around the world, Pacific-Basin Finance Journal 16, 411-435.

Cannavan, D., F. Finn, and S. Gray, 2004, The value of dividend imputation tax credits in Australia, Journal of Financial Economics 73, 167-197.

Clarkson, P., A. Nekrasov, A. Simon, and I. Tuttici, 2012, Target price forecasts: fundamentals and behavioral factors, Working paper (Business School, University of Queensland).

Collins, D. W., E. L. Maydew, and I. S. Weiss, 1997, Changes in the value-relevance of earnings and book values over the past forty years, Journal of Accounting and Economics 24, 39-67.

Daniel, K., and S. Titman, 1997, Evidence on the characteristics of cross sectional variation in stock returns, The Journal of Finance 52, 1-33. 
Dempsey, M., and G. Partington, 2008, Cost of capital equations under the Australian imputation tax system, Accounting and Finance 48, 439-460.

Dimson, E., 1979, Risk measurement when shares are subject to infrequent trading, Journal of Financial Economics 7, 197-226.

Dubofsky, D. A., 1992, A market microstructure explanation of ex-day abnormal returns, Financial Management 21, 32-43.

Duran, D., and A. M. May, 1960, The ex-dividend behavior of American Telephone and Telegraph stock, The Journal of Finance 15, 19-31.

Eades, K. M., P. J. Hess, and E. H. Kim, 1984, On interpreting security returns during the ex-dividend period, Journal of Financial Economics 13, 3-34.

Easton, P. D., and G. A. Sommers, 2006, Bias in expected rates of return implied by analysts' earnings forecasts, Working paper (Department of Accountancy, University of Notre Dame).

Elton, E. J., and M. J. Gruber, 1970, Marginal stockholder tax rates and the clientele effect, The Review of Economics and Statistics 52, 68-74.

Faff, R. W., 2001, An examination of the Fama and French three-factor model using commercially available factors, Australian Journal of Management 26, 1-17.

Faff, R. W., 2003, Creating Fama and French factors with style, Financial Review 38, 311-322.

Faff, R. W., 2004, A simple test of the Fama and French model using daily data, Applied Financial Economics 14, 83-92.

Fama, E. F., and K. R. French, 1993, Common risk factors in the returns on stocks and bonds, Journal of Financial Economics 33, 3-56.

Fama, E. F., and K. R. French, 1996, Multifactor explanations of asset pricing anomalies, The Journal of Finance 51, 55-84.

Fama, E. F., and K. R. French, 2002, Testing trade-off and pecking order predictions about dividends and debt, Review of Financial Studies 15, 1-33.

Fedenia, M., and T. Grammatikos, 1993, Risk premia and the ex-dividend stock price behavior, Journal of Banking and Finance 17, 575-589.

Fernandez, P., J. Aguirreamalloa, and L. C. Avendano, 2011, Equity market risk premium used in 56 countries in 2011, Working paper (IESE Business School, University of Navarra).

Feuerherdt, C., S. Gray, and J. Hall, 2010, The value of imputation tax credits on Australian hybrid securities, International Review of Finance 10, 365-401.

Fitzgerald, T., S. Gray, J. Hall, and R. Jeyaraj, 2013, Unconstrained estimates of the equity risk premium, Review of Accounting Studies 18, 560-639.

Frank, M., and R. Jagannathan, 1998, Why do stock prices drop by less than the value of the dividend?, Journal of Financial Economics 47, 161-188.

Frankel, R., and C. M. C. Lee, 1998, Accounting valuation, market expectation, and cross-sectional stock returns, Journal of Accounting and Economics 25, 283-319.

Freeman, R. N., and S. Y. Tse, 1992, A nonlinear model of security price responses to unexpected earnings, Journal of Accounting Research 30, 185-209.

Gordon, J. R., and M. J. Gordon, 1997, The finite horizon expected return model, Financial Analysts Journal 53, 52-61.

Graham, J. R., R. Michaely, and M. R. Roberts, 2003, Do price discreteness and transactions costs affect stock returns?, The Journal of Finance 58, 2611-2636.

Grammatikos, T., 1989, Dividend stripping, risk exposure, and the effect of the 1984 Tax Reform Act on the ex-dividend day behavior, The Journal of Business 62, 157173.

Gray, S. 2008, The Impact of Franking Credits on the Cost of Capital of Australian Firms (SFG Consulting, South Bank, QLD). 
Gray, S., and J. Hall, 2006, Relationship between franking credits and the market risk premium, Accounting and Finance 46, 405-428.

Gray, S., J. Hall, and D. Costello, 2011, Dividend Drop-off Estimate of Theta (SFG Consulting, South Bank, QLD).

Grubert, H., 2001, Tax planning by companies and tax competition by governments, in: J. R. Hines Jr, ed., International Taxation and Multinational Activity (University of Chicago Press, Chicago, IL), 113-139.

Guay, W., S. P. Kothari, and S. Shu, 2011, Properties of implied cost of capital using analysts' forecasts, Australian Journal of Management 36, 125-149.

Hathaway, N., and R. R. Officer, 2004, The Value of Imputation Tax Credits (Capital Research Pty Ltd., Melbourne, VIC).

Hayes, R. M., and C. B. Levine, 2000, An approach to adjusting analysts' consensus forecasts for selection bias, Contemporary Accounting Research 17, 61-83.

Heath, D. C., and R. A. Jarrow, 1988, Ex-dividend stock price behavior and arbitrage opportunities, The Journal of Business 61, 95-108.

Hou, K., M. A. van Dijk, and Y. Zhang, 2012, The implied cost of capital: an new approach, Journal of Accounting and Economics 53, 504-526.

Jakob, K., and T. Ma, 2004, Tick size, NYSE rule 118, and ex-dividend day stock price behavior, Journal of Financial Economics 72, 605-625.

Kalay, A., 1982, The ex-dividend day behavior of stock prices: a re-examination of the clientele effect, The Journal of Finance 37, 1059-1070.

Kalay, A., 1984, The ex-dividend day behavior of stock prices: a re-examination of the clientele effect (reply), The Journal of Finance 39, 557-561.

Karpoff, J. M., and R. A. Walkling, 1988, Short-term trading around ex-dividend days, Journal of Financial Economics 21, 291-298.

Karpoff, J. M., and R. A. Walkling, 1990, Dividend capture in NASDAQ stocks, Journal of Financial Economics 28, 39-65.

Lajbcygier, P., and S. M. Wheatley, 2012, Imputation credits and equity returns, The Economic Record 88, 476-494.

Lakonishok, J., and T. Vermaelen, 1986, Tax-induced trading around ex-dividend days, Journal of Financial Economics 16, 287-319.

Lally, M., 2000, Valuation of companies and projects under differential personal taxation, Pacific-Basin Finance Journal 8, 115-133.

Lally, M., 2008, Relationship between franking credits and the market risk premium: a comment, Accounting and Finance 48, 143-151.

Lally, M., and T. van Zijl, 2003, Capital gains tax and the Capital Asset Pricing Model, Accounting and Finance 43, 187-210.

Lee, C. M. C., E. C. So, and C. C. Y. Wang, 2010, Evaluating implied cost of capital estimates, Working paper (Stanford Graduate School of Business, Standford University).

Lustgarten, S., and V. Mande, 1998, The effect of insider trading on financial analysts' forecast accuracy and dispersion, Journal of Accounting and Public Policy 17, 311-327.

Michaely, R., and J.-L. Vila, 1995, Investors' heterogeneity, prices, and volume around the ex-dividend day, Journal of Financial and Quantitative Analysis 30, 171-198.

Miller, M. H., and F. Modigliani, 1961, Dividend policy, growth, and the valuation of shares, The Journal of Business 34, 411-433.

Minney, A., 2010, The valuation of franking credits to investors, Journal of Applied Finance 2, 29-34.

O'Brien, P. C., 1988, Analysts' forecasts as earnings expectations, Journal of Accounting and Economics 10, 53-83.

Officer, R. R., 1994, The cost of capital of a company under an imputation tax system, Accounting and Finance 34, 1-17. 
Ohlson, J. A., 1995, Earnings, book values, and dividends in equity valuation, Contemporary Accounting Research 11, 661-687.

Partington, G., and G. Truong, 2008, Relation between franking credits and the market risk premium, Accounting and Finance 48, 153-158.

Petersen, M. A., 2009, Estimating standard errors in finance panel data sets: comparing approaches, Review of Financial Studies 22, 435-480.

Powell, J., J. Shi, T. Smith, and R. Whaley, 2009, Common divisors, payout persistence, and return predictability, International Review of Finance 9, 225-257.

Statman, M., 1981, Betas compared: Merrill Lynch vs Value Line, Journal of Portfolio Management 7, 41-44.

Twite, G., and J. Wood, 2003, The pricing of Australian imputation tax credits, Working paper (Australian Graduate School of Management, University of New South Wales).

Walker, S., and G. Partington, 1999, The value of dividends: evidence from cumdividend trading in the ex-dividend period, Accounting and Finance 39, 275-296. 